\title{
Aging promotes acquisition of naive-like CD8+ memory $T$ cell traits and enhanced functionalities
}

\author{
Jens Eberlein, ${ }^{1,2}$ Bennett Davenport, ${ }^{1,2,3,4,5}$ Tom Nguyen, ${ }^{1,2}$ Francisco Victorino, ${ }^{1,2,3}$ Kelsey Haist, ${ }^{1,3}$ Kevin Jhun, ${ }^{4,5}$ \\ Anis Karimpour-Fard, ${ }^{6}$ Lawrence Hunter, ${ }^{6}$ Ross Kedl, ${ }^{3}$ Eric T. Clambey, ${ }^{1,3}$ and Dirk Homann ${ }^{1,2,3,4,5}$ \\ 'Department of Anesthesiology and 'Barbara Davis Center, University of Colorado Anschutz Medical Campus (UCAMC), Aurora, Colorado, USA. ${ }^{3}$ ntegrated Department of Immunology, UCAMC/National \\ Jewish Health, Aurora and Denver, Colorado, USA. ${ }^{4}$ Diabetes Obesity Metabolism Institute and ${ }^{5}$ Immunology Institute, Icahn School of Medicine at Mount Sinai, New York, New York, USA. \\ ${ }^{6}$ Center for Computational Pharmacology, UCAMC, Aurora, Colorado, USA
}

\begin{abstract}
Protective T cell memory is an acquired trait that is contingent upon the preservation of its constituents and therefore vulnerable to the potentially deleterious effects of organismal aging. Here, however, we have found that long-term T cell memory in a natural murine host-pathogen system can substantially improve over time. Comprehensive molecular, phenotypic, and functional profiling of aging antiviral $C D 8^{+}$memory $T$ cells $\left(C D 8^{+} T_{M}\right)$ revealed a pervasive remodeling process that promotes the gradual acquisition of distinct molecular signatures, of increasingly homogeneous phenotypes, and of diversified functionalities that combine to confer a $\mathrm{CD8}^{+} \mathrm{T}_{\mathrm{M}}$-autonomous capacity for enhanced recall responses and immune protection. Notably, the process of $\mathrm{CD8}^{+} \mathrm{T}_{M}$ aging is characterized by a progressive harmonization of memory and naive T cell traits, is broadly amenable to experimental acceleration or retardation, and serves as a constitutional component for the "rebound model" of memory $T$ cell maturation. By casting $C D 8^{+} T_{M}$ populations within the temporal framework of their slowly evolving properties, this model establishes a simple ontogenetic perspective on the principal organization of CD8 ${ }^{+} \mathrm{T}$ cell memory that may directly inform the development of improved diagnostic, prophylactic, and therapeutic modalities.
\end{abstract}

\section{Introduction}

The complex of aging, memory, and protection has long been recognized as a theme central to the immunological sciences. In at least one respect, though, this topic has not yet been explored in detail: how aging shapes and transforms the cardinal properties of $\mathrm{T}$ cell memory established early in life in response to acute infectious insults. The principal component of protective $\mathrm{T}$ cell memory is the population of pathogen-specific $\mathrm{CD} 8^{+}$memory $\mathrm{T}$ cells $\left(\mathrm{CD}^{+} \mathrm{T}_{\mathrm{M}}\right)$ that emerges, following resolution of acute disease, within several weeks through a process that combines the preferential survival of defined $\mathrm{CD}^{+}$effector $\mathrm{T}$ cell $\left(\mathrm{CD} 8^{+} \mathrm{T}_{\mathrm{E}}\right)$ subsets with their gradual maturation. The subsequent maintenance of specific $\mathrm{CD}^{+} \mathrm{T}_{\mathrm{M}}$ over extended time periods is integral to the organism's capacity to curtail secondary $\left(\mathrm{II}^{\circ}\right)$ infections, minimize clinical disease, and avert potential death (1-4). Conversely, any measures that modulate $\mathrm{CD}^{+} \mathrm{T}_{\mathrm{M}}$ homeostasis and preservation, including the process of aging, may also subvert effective immune protection. Indeed, a substantial body of literature demonstrates that aging can exert a wide-spread and often deleterious influence on the efficient coordination of $\mathrm{T}$ cell responses by compromising or distorting relevant organ systems (thymic involution), the distribution of $\mathrm{T}$ cell subsets (loss of naive $\mathrm{T}$ cells $\left[\mathrm{T}_{\mathrm{N}}\right.$ ], oligoclonal expansions of memory-phenotype $\mathrm{T}$ cells $\left.\left[\mathrm{T}_{\mathrm{MP}}\right]\right)$ and specificities (reduced TCR diversity), as well as altering $\mathrm{T}$ cell phenotypes,

Authorship note: J. Eberlein and B. Davenport contributed equally to this work Conflict of interest: The authors have declared that no conflict of interest exists. Submitted: May 13, 2016; Accepted: August 2, 2016.

Reference information: / Clin Invest. 2016;126(10):3942-3960. doi:10.1172/JCI88546. signal transduction, metabolism, telomere biology and functionalities (diminished responsiveness, exhaustion, replicative senescence, etc.) (5-10). Although the available evidence suggests that $\mathrm{CD}^{+} \mathrm{T}_{\mathrm{M}}$ populations maintained under ideal conditions (i.e., in the absence of persisting or deliberately introduced antigen) are less adversely affected by the ravages of age $(3,10)$, pathogenspecific $C D 8^{+} \mathrm{T}_{\mathrm{M}}$ appear to slowly evolve, as documented by their gradual though seemingly limited phenotypic and functional conversion (11-17). At a minimum, these observations emphasize the dynamic nature of $\mathrm{CD}^{+} \mathrm{T}_{\mathrm{M}}$ maturation, but they may also insinuate more extensive adaptations that $\mathrm{CD}^{+} \mathrm{T}_{\mathrm{M}}$ accrue over time and that may ultimately modify the efficacy of immune protection. In fact, a recent report by Martin et al. provided the first evidence for enhanced antiviral protection exerted by late ( $>8$ months after challenge) as compared with early (day 30-45) $\mathrm{CD}^{+} \mathrm{T}_{\mathrm{M}}$ (17).

To better define the nature, scope, and consequences of pathogen-specific $\mathrm{CD}^{+} \mathrm{T}_{\mathrm{M}}$ aging, we employed a natural host-pathogen system - the acute infection of mice with lymphocytic choriomeningitis virus (LCMV) - and delineated the progressive accumulation of distinctive molecular, phenotypic, and functional properties of $\mathrm{CD}^{+} \mathrm{T}_{\mathrm{M}}$ populations maintained for life. Our results demonstrate that aging of antiviral $\mathrm{CD}^{+} \mathrm{T}_{\mathrm{M}}$ is defined by a prolonged and pronounced molecular remodeling process that is associated with the acquisition of a unique, more homogeneous phenotype emulating the appearance of naive $\mathrm{CD}^{+} \mathrm{T}$ cells $\left(\mathrm{CD}^{+} \mathrm{T}_{\mathrm{N}}\right)$. Furthermore, this remodeling process imparts surprisingly favorable traits onto aged $\mathrm{CD}^{+}$ $\mathrm{T}_{\mathrm{M}}$ (diversified effector functionalities, enhanced $\mathrm{II}^{\circ}$ reactivity, and improved protective capacity) and can be accelerated or 
restrained as a whole by modulating the extent and/or speed of primary $\left(\mathrm{I}^{\circ}\right) \mathrm{CD} 8^{+} \mathrm{T}_{\mathrm{E}}$ differentiation.

Beyond the context of aging, however, the primacy of temporal relationships between multiple $\mathrm{CD} 8^{+} \mathrm{T}_{\mathrm{M}}$ subsets outlined here permits the development of a potentially novel perspective on the generation and maintenance of $\mathrm{CD} 8^{+} \mathrm{T}$ cell memory that correlates protective potential with a progressive alignment of $\mathrm{CD}^{+} \mathrm{T}_{\mathrm{M}}$ and $\mathrm{T}_{\mathrm{N}}$ properties, that posits a dedifferentiation process as a core feature of $\mathrm{CD} 8^{+} \mathrm{T}$ cell memory in general, and that we have organized in a modification of the decreasing potential model $(1,4)$ termed the "rebound model" of $\mathrm{CD}^{+} \mathrm{T}_{\mathrm{M}}$ maturation. The notion that dedifferentiated $C D 8^{+} \mathrm{T}_{\mathrm{M}}$ with defined molecular traits, phenotypic signatures, and functional properties can provide enhanced protection will likely have practical implications for public health initiatives such as the design of immunization strategies, monitoring of vaccine efficacy, and the development of improved treatment modalities for infectious diseases.

\section{Results}

Enhanced $I I^{\circ}$ reactivity of aged $C D 8^{+} T_{M}$. The LCMV model of acute viral infection permits the generation of specific $C D 8^{+} \mathrm{T}_{M}$ that are maintained for life and poised to be effectively recruited into a $\mathrm{II}^{\circ}$ response (11). To assess the recall potential of aging $C D 8^{+} T_{M}$ populations in greater detail, we utilized an in vivo system in which $\mathrm{II}^{\circ}$ expansions of both young and old $\mathrm{CD}^{+} \mathrm{T}_{\mathrm{M}}$ populations could be monitored within the same host. In brief, cohorts of young adult B6 and B6-congenic mice were challenged with LCMV in a staggered fashion and allowed to age for up to $\sim 2$ years. Young (d58 after infection) and old (d850) $\mathrm{CD}^{+} \mathrm{T}_{\mathrm{M}}$ were then isolated, mixed at a ratio of 1:1, and adoptively transferred (AT) into naive congenic recipients that were challenged with LCMV (Figure 1A). Despite their advanced age, old $\mathrm{CD} 8^{+} \mathrm{T}_{\mathrm{M}}$ consistently gave rise to greater $\mathrm{II}^{\circ} \mathrm{CD} 8^{+} \mathrm{T}_{\mathrm{E}}$ expansions, a phenomenon that is observed in lymphatic and nonlymphoid tissues alike and independent of the particular choice of congenic T cell marker (Figures 1, A and B, and Supplemental Figure 1A; supplemental material available online with this article; doi:10.1172/JCI88546DS1). Similar findings were originally reported for the Sendai virus system (14) and more recently also for Listeria monocytogenes and LCMV models $(16,17)$, providing evidence for the more general occurrence of this phenomenon and a rationale for further investigations into the nature of $C D 8^{+} \mathrm{T}_{\mathrm{M}}$ recall responses that, paradoxically, improve with age.

Differentiating LCMV-specific CD8 ${ }^{+} \mathrm{T}$ cell responses according to $7 \mathrm{MHC}$-I-restricted epitopes, we found the age-associated augmentation of $\mathrm{II}^{\circ} \mathrm{CD}^{+} \mathrm{T}_{\mathrm{E}}$ expansions to be independent of immunodominant determinants and functional avidities, an observation that was also reflected in the comparable frequencies of specific $\mathrm{II}^{\circ} \mathrm{CD} 8^{+} \mathrm{T}_{\mathrm{E}}$ within the respective young and old donor $\mathrm{CD} 8^{+} \mathrm{T}$ cell compartments (Figure $1 \mathrm{C}$ and Supplemental Figure 1B). Indeed, as determined by granzyme B (GZMB) and CCL5 content $(12,18)$, the entire pool of expanded donor $\mathrm{CD} 8^{+} \mathrm{T}$ cells bore hallmarks of specific activation, and both young and old $\mathrm{II}^{\circ} \mathrm{CD} 8^{+}$ $\mathrm{T}_{\mathrm{E}}$, regardless of their differential expansion, exhibited a comparable spectrum of inducible functionalities (Supplemental Figure $1, \mathrm{C}$ and $\mathrm{D})$. The improved accumulation of $\mathrm{II}^{\circ} \mathrm{CD} 8^{+} \mathrm{T}_{\mathrm{E}}$ derived from old $\mathrm{CD} 8^{+} \mathrm{T}_{\mathrm{M}}$ must be grounded in their enhanced proliferation and/or survival, and to distinguish between these possibilities we determined expansion kinetics, proliferation rates, and survival of $\mathrm{CD}^{+} \mathrm{T}_{\mathrm{E}}$ throughout the $\mathrm{II}^{\circ}$ response. In the experimental setting employed here, $\mathrm{II}^{\circ} \mathrm{CD} 8^{+} \mathrm{T}_{\mathrm{E}}$ typically start to divide only more than 48 hours after LCMV infection (19), and the comparable proliferation indices and $\mathrm{II}^{\circ} \mathrm{CD} 8^{+} \mathrm{T}_{\mathrm{E}}$ numbers found in the spleen 60 hours after challenge demonstrated that young and old $C D 8^{+} \mathrm{T}_{\mathrm{M}}$ were recruited into the peripheral $\mathrm{II}^{\circ}$ response with similar kinetics (Figure 1D). Differential expansion of $\mathrm{II}^{\circ} \mathrm{CD} 8^{+} \mathrm{T}_{\mathrm{E}}$, however, became apparent in blood and spleen on day 5 after AT/ rechallenge, was further amplified on subsequent days (Figure 1, $\mathrm{D}$ and $\mathrm{E}$ ), and primarily emerged through the better survival of old $\mathrm{II}^{\circ} \mathrm{CD} 8^{+} \mathrm{T}_{\mathrm{E}}$ rather than their faster or prolonged proliferation (Supplemental Figure 1, E-G).

Kinetics of early $\mathrm{II}^{\circ} \mathrm{CD} 8^{+} T_{E}$ expansions in draining and nondraining lymph nodes (LNs). In order to visualize the earliest events of the $\mathrm{II}^{\circ}$ response in vivo, we resorted to the p14 chimera system: purified naive p14 cells (TCRtg CD $8^{+} \mathrm{T}$ cells specific for the LCMV-GP ${ }_{33}$ determinant) were transferred into $\mathrm{B} 6$ recipients that were inoculated with LCMV and subsequently served as donors for $\mathrm{p} 14^{+} \mathrm{T}_{\mathrm{M}}$. Within 48 hours after $\mathrm{p} 14^{+} \mathrm{T}_{\mathrm{M}} \mathrm{AT} / \mathrm{rech}$ allenge, old but not young $\mathrm{II}^{\circ} \mathrm{p} 14^{+} \mathrm{T}_{\mathrm{E}}$ largely disappeared from the circulation (Figure $1 \mathrm{~F}$ ), suggesting their sequestration to other tissues, most likely LNs (20). In the ensuing 16 hours, old $\mathrm{II}^{\circ} \mathrm{p} 14^{+} \mathrm{T}_{\mathrm{E}}$ returned to the blood, and both young and old II ${ }^{\circ} \mathrm{p} 14^{+} \mathrm{T}_{\mathrm{E}}$ began to proliferate at a comparable pace in the spleen (Figure $1 \mathrm{G}$ ). At the same time, however, old and young $\mathrm{II}^{\circ} \mathrm{p} 14^{+} \mathrm{T}_{\mathrm{E}}$ responses already began to diverge in the LNs, especially the draining mediastinal LNs (MedLNs) (21) where enhanced proliferation rates of aged $\mathrm{II}^{\circ} \mathrm{p} 14^{+} \mathrm{T}_{\mathrm{E}}$ correlated with their significantly increased numbers (Figure $1 \mathrm{H}$ ). These observations could also be extended to the $\mathrm{B} 6$ system and the first emergence of differential $\mathrm{II}^{\circ} \mathrm{CD} 8^{+} \mathrm{T}_{\mathrm{E}}$ expansions on day 5 after challenge: here, old outnumbered young $\mathrm{II}^{\circ} \mathrm{D}^{\mathrm{b}} \mathrm{NP}_{396}{ }^{+} \mathrm{CD} 8^{+} \mathrm{T}_{\mathrm{E}}$ by a factor of $\sim 3$ in the MedLNs but by less than 2-fold in blood, spleen, and other LNs (Figure 1, E and I). Thus, greater II ${ }^{\circ}$ expansions of aged $\mathrm{II}^{\circ} \mathrm{CD}^{+} \mathrm{T}_{\mathrm{E}}$, driven from day 5 onwards primarily by a survival advantage, were precipitated between days 2 and 4 by an earlier onset of proliferation in LNs, in particular the MedLNs.

Improved protective capacity of aged $C D 8^{+} T_{M}$ as a $T_{M}$-intrinsic property. Taken together, our results suggest that aging $C D 8^{+} \mathrm{T}_{\mathrm{M}}$ acquire certain intrinsic properties, although the potential influence of several variables such as recipient age and adaptive changes of transferred $\mathrm{CD} 8^{+} \mathrm{T}_{\mathrm{M}}$, contemporaneous $\mathrm{I}^{\circ}$ responses generated by the host, and a direct competition between concurrent $\mathrm{II}^{\circ} \mathrm{CD} 8^{+} \mathrm{T}_{\mathrm{E}}$ responses has not yet been ascertained. To determine if the acquisition of enhanced $\mathrm{II}^{\circ}$ reactivity by aging $\mathrm{CD} 8^{+} \mathrm{T}_{\mathrm{M}}$ simply constituted a natural adaptation that could be reversed upon prolonged exposure to a young host environment or rather was restricted to that particular environment, we conducted complementary mixed AT/ rechallenge experiments and found that neither extended parking of transferred cells prior to infection nor advanced host age affected the differential expansion of old versus young $\mathrm{II}^{\circ} \mathrm{CD} 8^{+} \mathrm{T}_{\mathrm{E}}$ (Figure 2, $\mathrm{A}$ and $\mathrm{B})$. Since the AT of low $\mathrm{CD} 8^{+} \mathrm{T}_{\mathrm{M}}$ numbers does not preclude the development of simultaneous host $\mathrm{T}$ cell responses directed against the same LCMV determinants, we also monitored $\mathrm{I}^{\circ} \mathrm{CD} 8^{+}$ $\mathrm{T}_{\mathrm{E}}$ populations generated by young and old recipients. Interestingly, and consistent with the notion that aged mice have a reduced capacity to mount de novo antiviral $\mathrm{CD} 8^{+} \mathrm{T}_{\mathrm{E}}$ responses (22), the advanced 


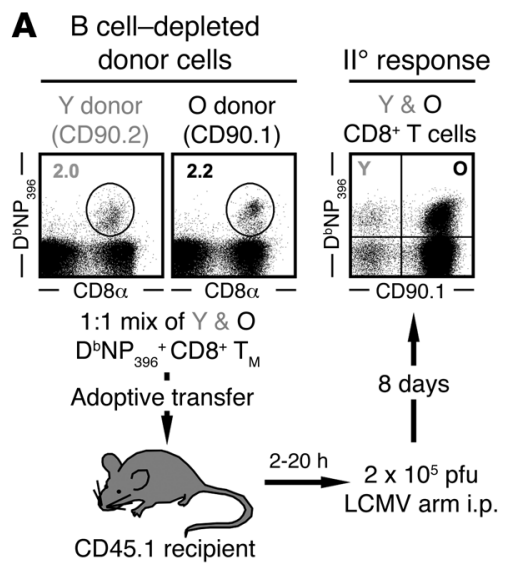

B

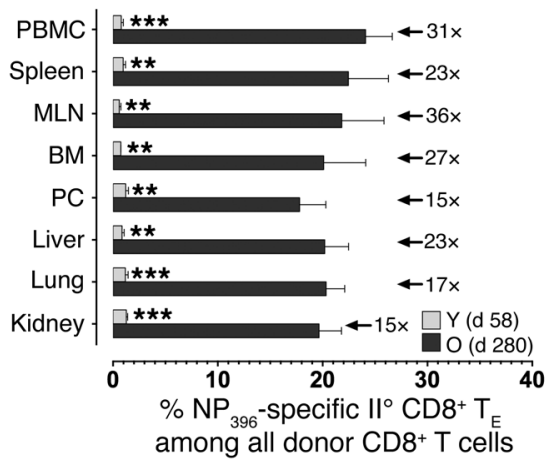

C $\quad I^{\circ} \mathrm{NP}_{396}$-specific CD8 ${ }^{+} \mathrm{T}_{\mathrm{E}}$ frequencies

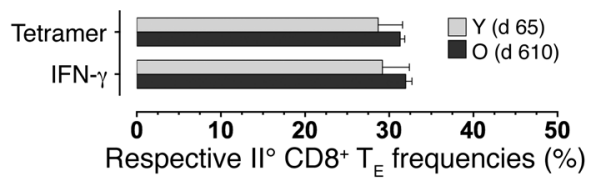

D

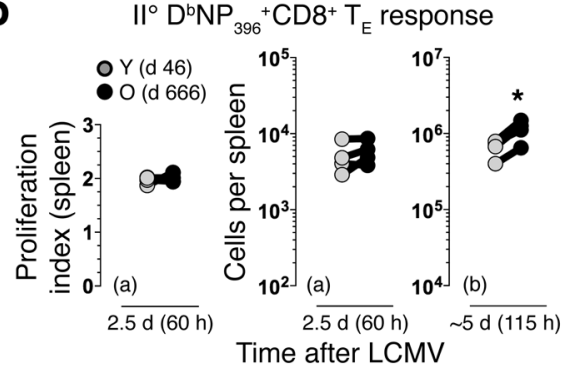

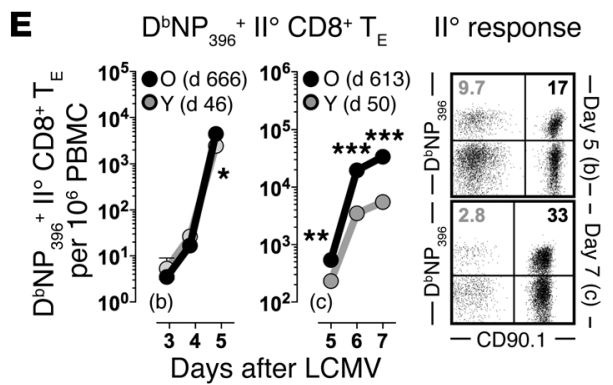
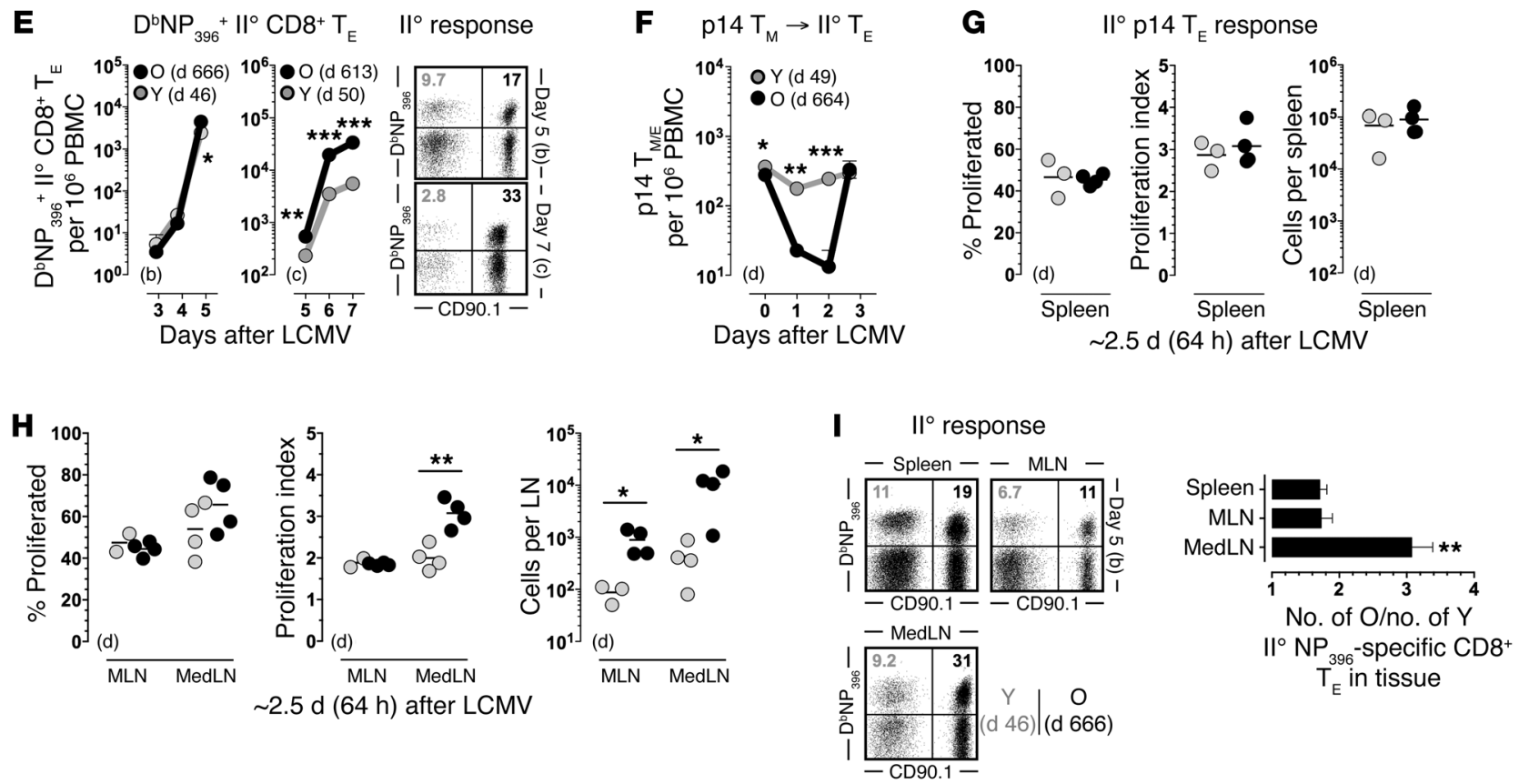

Figure 1. Enhanced II reactivity of aged $\mathrm{CD8}^{+} \mathbf{T}_{\mathrm{M}^{*}}$ (A) Outline for mixed AT/rechallenge experiments. Unless noted otherwise, $C D 8^{+} \mathrm{T}$ cell-enriched popula-

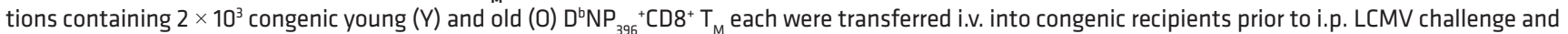
analysis of $I^{\circ} \mathrm{CD}^{+} \mathrm{T}_{\mathrm{E}}$ expansions on day 8. (B) Relative frequencies of $\mathrm{II}^{\circ} \mathrm{D}^{\mathrm{b}} \mathrm{NP}_{396}{ }^{+} \mathrm{CD} 8^{+} \mathrm{T}_{\mathrm{E}}$ among all donor CD8 ${ }^{+} \mathrm{T}$ cells; donor age (time after $\mathrm{I}^{\circ} \mathrm{LCMV}$ challenge), factor of differential II expansion and statistical significance are indicated. (C) Respective frequencies of $\mathrm{NP}_{396}{ }^{-5 p e c i f i c} \mathrm{II}^{\circ} \mathrm{CD}^{+} \mathrm{T}_{\mathrm{E}}$ in young and old CD8 ${ }^{+}$donor T cell compartments as assessed by tetramer or IFN- $\gamma$ staining. (D) Mixed AT/rechallenge experiments were conducted with CFSE-labeled donor cells to calculate proliferation indices; corresponding data points from individual recipients are connected by a line. (E) Expansion kinetics of $I^{\circ} C D 8^{+} T_{E}$ in

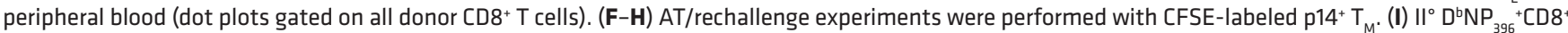
$T_{E}$ responses analyzed on day 5. To visualize earlier stages of the $I^{\circ}$ response in panels $\mathbf{D}-\mathbf{I}$, escalating numbers of CD8 ${ }^{+} \mathrm{T}$ cell-enriched donor populations were transferred containing (a) $2 \times 10^{5}$, (b) $4 \times 10^{4}$ or (c) $5 \times 10^{3}$ young and old $D^{b} \mathrm{NP}_{396}{ }^{+} \mathrm{CD}^{+}{ }^{+} \mathrm{T}_{\mathrm{M}}$ each, or (d) $1 \times 10^{6} \mathrm{p} 14^{+} \mathrm{T}_{\mathrm{M}}$. Data are the mean $\pm 1 \mathrm{SEM}$ or feature individual data points with $n \geq 3$ mice for multiple independent experiments. ${ }^{*} P<0.05,{ }^{*} P<0.01$, and ${ }^{* * *} P<0.001$ by 1 way ANOVA or Student's $t$ test. BM, bone marrow; MedLN, mediastinal lymph nodes; MLN, mesenteric lymph nodes; PBMC, peripheral blood mononuclear cells; PC, peritoneal cavity.

age of recipient mice significantly compromised their $\mathrm{I}^{\circ} \mathrm{CD} 8^{+} \mathrm{T}_{\mathrm{E}}$ responses despite the fact that it readily supported enhanced $\mathrm{II}^{\circ}$ expansions of aged $\mathrm{CD}^{+} \mathrm{T}_{\mathrm{M}}$ (Figure 2B). While these data suggest an at least partially independent regulation of $\mathrm{I}^{\circ}$ and $\mathrm{II}^{\circ} \mathrm{CD} 8^{+} \mathrm{T}$ cell immunity, a direct evaluation of this contention required a model system in which $\mathrm{II}^{\circ} \mathrm{CD}^{+} \mathrm{T}$ cell immunity could be studied in the complete absence of concurrent $\mathrm{I}^{\circ} \mathrm{T}$ cell responses: OT-I mice, due to their skewed TCR specificity for ovalbumin, cannot generate
LCMV-specific $\mathrm{T}$ cell responses, but otherwise provide a $\mathrm{T}$ cellreplete in vivo environment that eschews artifacts associated with $\mathrm{T}$ cell deficiency (23). As shown in Figure 2C, the disparate reactivity of old versus young $\mathrm{CD}^{+} \mathrm{T}_{\mathrm{M}}$ was preserved in OT-I recipients, indicating that their differential $\mathrm{II}^{\circ}$ reactivity is not affected by contemporaneous $\mathrm{I}^{\circ} \mathrm{CD}^{+} \mathrm{T}_{\mathrm{E}}$ responses.

We next addressed the issues of potential competition among $\mathrm{II}^{\circ} \mathrm{CD}^{+} \mathrm{T}_{\mathrm{E}}$ populations and immune protection by 
A

Delayed challenge

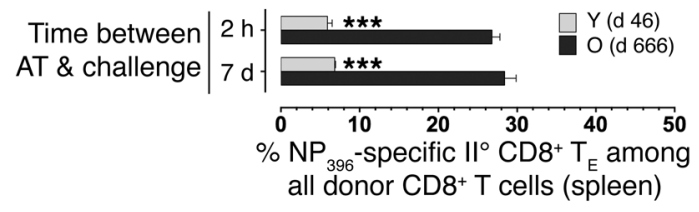

B

Y vs. O recipients
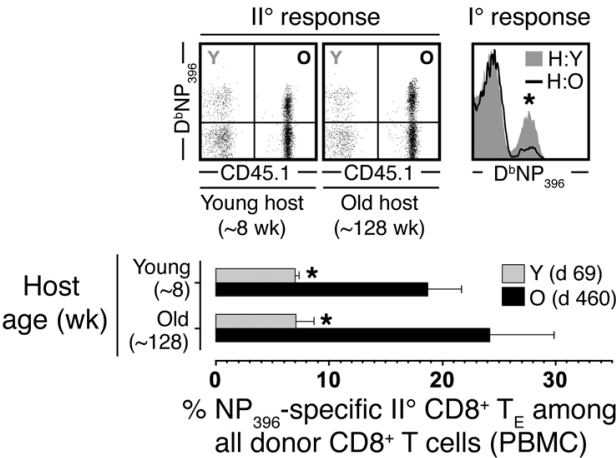

C

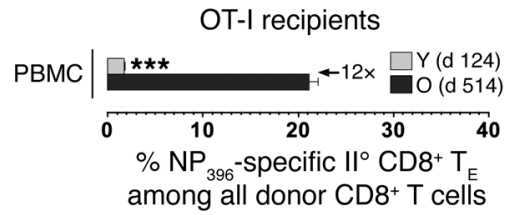

D

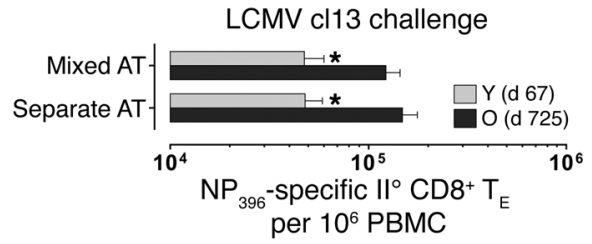

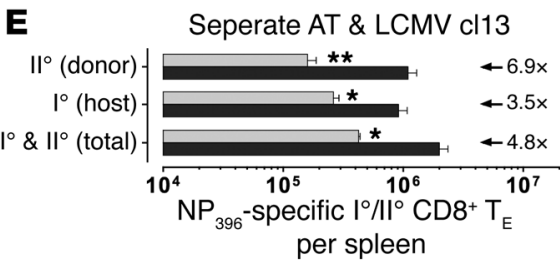

$\mathbf{F}$

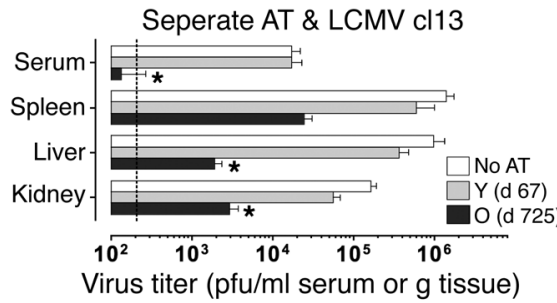

OT-I recipients

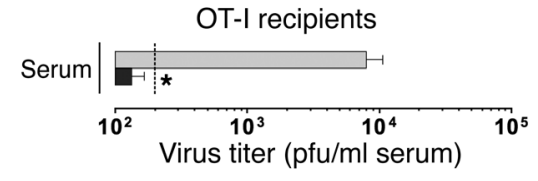

G

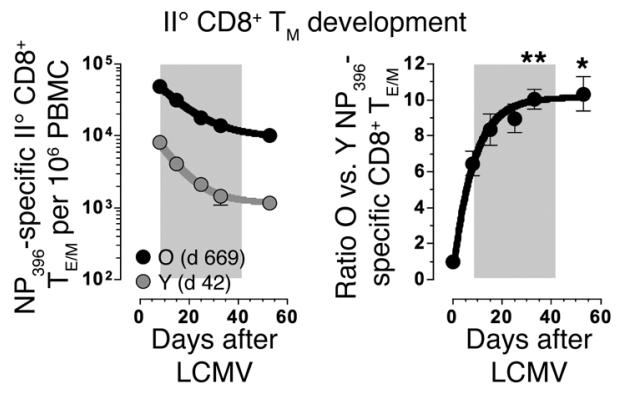

Figure 2. Improved protective capacity of aged $\mathrm{CD8}^{+} \mathrm{T}_{\mathrm{M}}$ as a $\mathrm{T}_{\mathrm{M}}$-intrinsic property. (A) Recipients of mixed young $(\mathrm{Y})$ and old $(0) \mathrm{D}^{\mathrm{b}} \mathrm{NP}{ }_{396}{ }^{+} \mathrm{CD8} 8^{+} \mathrm{T}_{\mathrm{M}}$ populations $\left(5 \times 10^{3}\right.$ each) were challenged 2 hours or 7 days after AT. (B) $I^{\circ}$ expansions of young vs. old CD8 ${ }^{+} T_{M}$ transferred into naive young vs. old recipients.

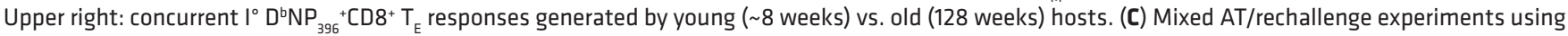
OT-I recipients. (D) Young and old donor cells depleted of B and CD4+ T cells were combined or transferred separately prior to LCMV cl13 challenge. (E) Quantification of concurrent $\mathrm{I}^{\circ}$ and $\mathrm{II}^{\circ} \mathrm{CD} 8^{+} \mathrm{T}_{\mathrm{E}}$ responses after separate AT/LCMV cl13 rechallenge as performed in panel $\mathbf{D}$. (F) Top, virus titers in tissues (day 8 ) after separate AT/LCMV cl13 rechallenge; bottom, AT of $5 \times 10^{3} \mathrm{D}^{\mathrm{b} N P_{396}}{ }^{+} \mathrm{CD} 8^{+} \mathrm{T}_{\mathrm{M}}$, OT-I recipients and determination of viral titers on day 6 . (C) Contraction kinetics of $1{ }^{\circ} \mathrm{CD}^{+} \mathrm{T}_{\mathrm{E}}$ populations after LCMV Armstrong challenge; asterisks indicate a significant rise of the 0:Y ratio as compared with day 8 (gray background = contraction phase); data generated with $n \geq 3$ mice/group in multiple independent experiments. ${ }^{*} P<0.05,{ }^{* *} P<0.01$, and ${ }^{* * *} P<0.001$ by 1 way ANOVA or Student's $t$ test. PBMC, peripheral blood mononuclear cells.

use of mixed versus separate AT experiments and rechallenge with high-dose LCMV clone13 (cl13). Here, LCMV cl13-infected recipients of old and young $\mathrm{CD} 8^{+} \mathrm{T}_{\mathrm{M}}$, whether transferred separately or in combination, supported the enhanced $\mathrm{II}^{\circ}$ proliferation of aged $\mathrm{CD}^{+} \mathrm{T}_{\mathrm{M}}$ in an identical fashion, ruling out that differential expansion resulted from direct competition between $\mathrm{II}^{\circ} \mathrm{CD} 8^{+} \mathrm{T}_{\mathrm{E}}$ populations (Figure $2 \mathrm{D}$ ). We also note that the heightened $\mathrm{II}^{\circ}$ expansion of aged $\mathrm{CD} 8^{+} \mathrm{T}_{\mathrm{M}}$ in fact boosted $I^{\circ}$ LCMV-specific CD8 ${ }^{+} T_{E}$ reactivity, a likely consequence of accelerated virus control (Figure 2E). Indeed, as determined by infectious virus titers in the separate AT/LCMV cl13 rechallenge experiments and similar to the findings of Martin et al. (17), aged $\mathrm{CD} 8^{+} \mathrm{T}_{\mathrm{M}}$ populations mediated significantly enhanced immune protection (Figure $2 \mathrm{~F}$ ), a phenomenon also observed in OT-I recipients and thus in an experimental scenario where
LCMV-specific T cell responses are exclusively derived from the donor population (Figure 2F).

We also monitored the generation of $\mathrm{II}^{\circ} \mathrm{CD} 8^{+} \mathrm{T}_{\mathrm{M}}$ cells using the mixed AT/LCMV Armstrong rechallenge protocol and confirmed the attenuated contraction of $\mathrm{II}^{\circ}$ in relation to $\mathrm{I}^{\circ} \mathrm{CD} 8^{+} \mathrm{T}_{\mathrm{E}}$ populations (24) (Figure 2G and not shown). Importantly, a lesser contraction of aged as compared with young $\mathrm{II}^{\circ} \mathrm{CD} 8^{+} \mathrm{T}_{\mathrm{E}}$ further amplified their numerical differences and promoted a pronounced disparity of respective $\mathrm{II}^{\circ} \mathrm{CD} 8^{+} \mathrm{T}_{\mathrm{M}}$ pool sizes (Figure $2 \mathrm{G}$ ). Altogether, these observations demonstrate that antiviral $\mathrm{CD} 8^{+} \mathrm{T}_{\mathrm{M}}$ are subject to an extended maturation process that results in the acquisition of $\mathrm{CD}^{+} \mathrm{T}_{\mathrm{M}}$-intrinsic properties that foster enhanced $\mathrm{II}^{\circ}$ reactivity, immune protection, and $\mathrm{II}^{\circ} \mathrm{CD} 8^{+} \mathrm{T}_{\mathrm{M}}$ potential.

Global phenotypic and molecular alterations of aging antiviral $C D 8^{+} T_{M^{*}}$ Given the relative dearth of knowledge about the mod- 
A

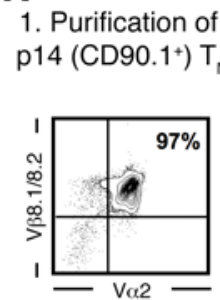

2. Transfer of purified $\mathrm{p} 14$

$\left(C D 90.1^{+}\right) \mathrm{T}_{N}$ into B6 (CD90.2+)

recipients and infection

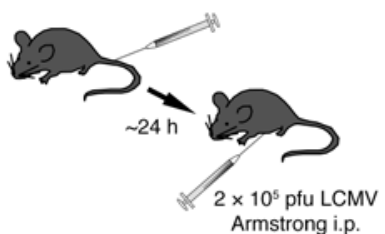

3. Staggered cohorts of aging LCMV-immune p14 chimeras
4. Purification of p14 (CD90.1+) $\mathrm{T}_{\mathrm{EM}}$

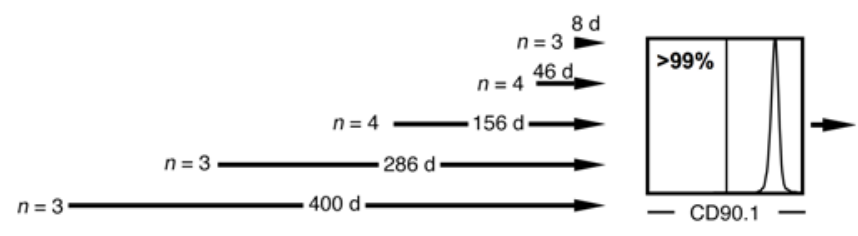

RNA extraction, amplification \& array hybridization (Affimetrix mouse genome 4302.0 )

B

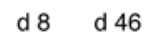
d 156

d 286

\section{C}

Time after LCMV infection (d)

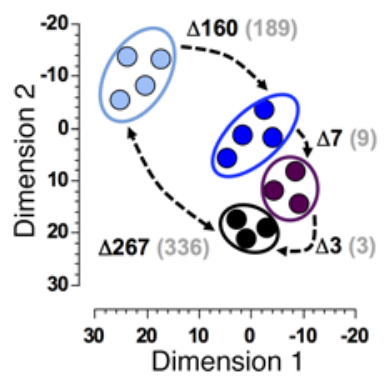

D
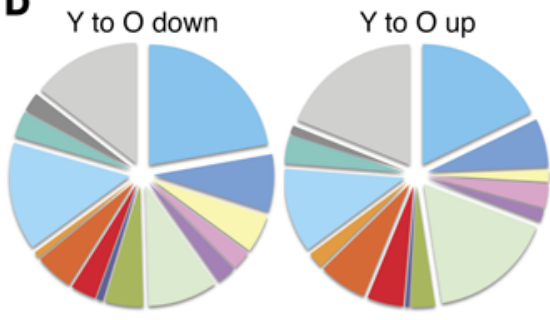

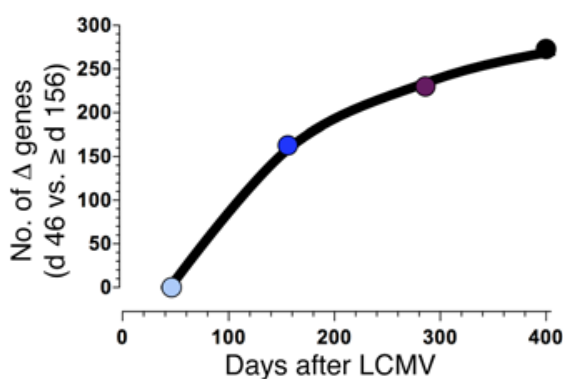

Surface receptors (excl. chemokine receptors) Cellular migration and morphology Effector molecules (secreted)

Survival/apoptosis

Ion channels and transmembrane transporters Intracellular signal transduction Intracellular trafficking

Histone modifiers

Regulation of cell cycle and development

Metabolism/ion homeostasis

Lipid catabol./metabolism/transport/homeost.

Transcription/RNA modifiers

Translation/PTM

Mitochondrial genes

Various and unknown
C

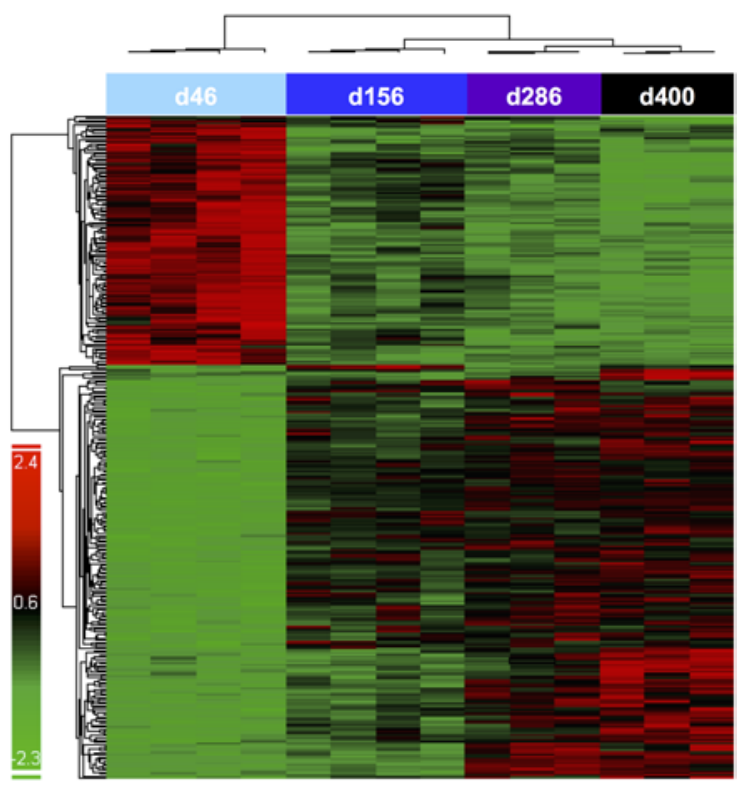

Figure 3. Molecular remodeling of aging antiviral CD8 ${ }^{+} \mathbf{T}_{\mathrm{M}^{*}}$ (A) Generation of LCMV-immune p14 chimeras (B6 mice transduced with $5 \times 10^{4}$ purified congenic $p 14^{+} T_{N}$ prior to LCMV infection) was performed in a staggered fashion such that isolation of splenic p14+ $T_{E}$ (day 8 ) and $p 14^{+} T_{M}$ (days $46,156,286$, and 400) could be performed at the same time. (B) Top, timeline/color code for microarray analyses of purified p14 ${ }^{+} T_{E / M}$; bottom left, MDS analysis of DEGs $(P<0.05$, FDR $<5 \%)$; numbers represent DEGs (black) and individual probe sets (gray) comparing the indicated p14 ${ }^{+} \mathrm{T}_{M}$ populations $(P<0.05$, fold change $>$ 2.0); bottom right, numbers of DEGs comparing day-46 and older $14^{+} T_{M^{*}}$ (C) Heat-map clustering of $p 14^{+} T_{M} D E G s$. (D) Distribution of p14+ $T_{M} D E G s$ (day 46 [Y] vs. day 400 [0]; see Supplemental Table 1) across 15 major gene ontology categories.

ulation of pathogen-specific $\mathrm{CD}^{+} \mathrm{T}_{\mathrm{M}}$ maintained for extended periods of time, we performed an initial survey of aging LCMVimmune mice to detail the temporal regulation of major antigens expressed by specific $\mathrm{CD}^{+} \mathrm{T}_{\mathrm{M}}$. Perhaps surprisingly, none of these markers nor cellular size or granularity/complexity were maintained at stable levels. Ranging from the marginal (cell size and granularity/complexity) to the modest $\left(\mathrm{CD} 44^{+} \mathrm{CD} 45^{+} \mathrm{TCRV} \beta^{+}\right.$ $\mathrm{CD} 3 \varepsilon^{+} \mathrm{CD} 8 \alpha$ ) and more pronounced $\left(\mathrm{MHC}-\mathrm{I}^{+} \mathrm{CD} 90^{+}\right)$, specific $\mathrm{CD} 8^{+} \mathrm{T}_{\mathrm{M}}$ properties were subject to an extended maturation process that lasted for at least $\sim 2$ years and introduced significant increases among all parameters evaluated (Supplemental Figure 2).

To delineate the extent of molecular remodeling in aging antiviral $\mathrm{CD}^{+} \mathrm{T}_{\mathrm{M}}$, we generated LCMV-immune chimeras in a staggered fashion followed by contemporaneous purification of $\mathrm{I}^{\circ}$ $\mathrm{p} 14^{+} \mathrm{T}_{\mathrm{E}}(\mathrm{d} 8)$ and $\mathrm{T}_{\mathrm{M}}(\mathrm{d} 46, \mathrm{~d} 156, \mathrm{~d} 286$, and $\mathrm{d} 400)$ from individual mice, and processing for microarray hybridization (Figure $3 \mathrm{~A}$ ). Basic microarray analyses were conducted using both PGS (Fig- ure 3, B and C) and Genespring (Figure 3D) software and yielded essentially similar results: multidimensional scaling (MDS) of differentially expressed genes (DEGs) in individual $\mathrm{p} 14^{+} \mathrm{T}_{\mathrm{M}}$ populations demonstrated distinctive clustering according to age; molecular differences accrued with a diminishing pace over time; and unsupervised hierarchical clustering identified 2 clusters of genes, the expression of which progressively decreased (117 genes, 2/5 DEGs) or increased (185 genes, 3/5 DEGs) with age (Figure 3, B and $\mathrm{C}$, and Supplemental Table 1).

Manual classification of DEGs into broad gene ontologyinspired categories revealed a relative dominance of cell surface receptors/ligands, migration- and morphology-associated genes, and intracellular signaling molecules, suggesting that $\mathrm{CD}^{+} \mathrm{T}_{\mathrm{M}}$ aging may be accompanied by alterations of their phenotypes and reactivities (Figure 3D). Indeed, ingenuity pathway analysis (IPA) identified several canonical signaling pathways that included cytokines, chemokines/receptors, major costimulato- 
Table 1. Rank-ordered listing of genes exhibiting $>5$-fold downregulation in old (day 400) vs. young (day 46) $\mathrm{p14}^{+} \mathrm{T}_{\mathrm{M}}$ and corresponding differential protein expression by $\mathrm{D}^{\mathrm{b}} \mathrm{NP}_{396}{ }^{+}{ }^{+} \mathrm{CD}^{+} \mathrm{T}_{\mathrm{M}}$

\begin{tabular}{|c|c|c|c|c|c|}
\hline \multirow[b]{2}{*}{ Rank } & \multicolumn{3}{|c|}{ Genes downregulated $>5$-fold by aging $\mathrm{p}^{1} 4^{+} \mathrm{T}_{\mathrm{M}}$} & \multicolumn{2}{|c|}{ Proteins downregulated by aging $\mathrm{D}^{\mathrm{b}} \mathrm{NP}_{396}{ }^{+} \mathrm{CD} 8^{+} \mathrm{T}_{\mathrm{M}}$} \\
\hline & Gene ID & Gene & $\mathrm{FC}^{\mathrm{A}}$ & $\mathrm{FC}$ & Figure \\
\hline 1 & 14938 & Gzma & -88.2 & -10.4 & $7 \mathrm{~A}$ \\
\hline 2 & $16634 / 40$ & Klra3/Klrag & -45.2 & -3.4 & $4 \mathrm{~A}$ \\
\hline 3 & 241447 & Lass6 & -32.5 & & \\
\hline 4 & 20308 & Ccl9 & -27.8 & -1.7 & Unpublished ${ }^{\mathrm{B}}$ \\
\hline 5 & 11658 & Alcam (CD166) & -25.8 & -2.0 & S10A \\
\hline 6 & 13051 & {$[\times 3 c r 1$} & -20.7 & -7.0 & $10 \mathrm{~A}$ \\
\hline 7 & 15277 & $H k 2$ & -15.7 & & \\
\hline 8 & 16364 & IIf4 & -12.4 & & \\
\hline 9 & 243655 & Klre1 & -12.2 & not translated & $4 \mathrm{~A}$ \\
\hline 10 & 17059 & Klrb1c & -11.7 & -3.5 & $4 \mathrm{~A}$ \\
\hline 11 & 103012 & Firre & -10.4 & & \\
\hline 12 & 433470 & AA467197 (Nmes1) & -9.5 & & \\
\hline 13 & 14425 & Calnt3 & -8.0 & & \\
\hline 14 & 57916 & Tnfrsf13b (TACI) & -7.6 & not translated & $\mathrm{S} 7$ \\
\hline 15 & 74103 & Nebl & -7.5 & & \\
\hline 16 & 20947 & Swap70 & -7.0 & & \\
\hline 17 & 50928 & Klrg1 & -7.0 & -3.0 & $4 \mathrm{~A}$ \\
\hline 18 & 19713 & Ret & -6.9 & -1.8 & $S 10 C$ \\
\hline 19 & 20305 & Ccl6 & -6.1 & not translated & Unpublished $^{\mathrm{B}}$ \\
\hline 20 & 72661 & Serp2 & -5.8 & & \\
\hline 21 & 77647 & Trat1 (TRIM) & -5.5 & -1.1 & S8B \\
\hline 22 & 21413 & Tcf4 & -5.3 & & \\
\hline 23 & 27218 & Slamf1 (CD150) & -5.3 & not translated & S9A \\
\hline 24 & 16639 & Klra8 & -5.2 & not translated & $4 \mathrm{~A}$ \\
\hline
\end{tabular}

${ }^{A}$ All fold-changes (FC) are significant (genes, adjusted $P<0.0025$; proteins, $P<0.05$ ) (1-way ANOVA). Bunpublished observations (JE and DH).

belonged to the same subgroup of C-type lectins, the KLR family (Table 1). We therefore broadened our analytical strategy to investigate the temporal regulation of all murine KLR members. Here, among the 11 of 45 KLR genes present in $\mathrm{p}^{+} 4^{+} \mathrm{T}_{\mathrm{M}}, 10$ demonstrated a progressive and significant downmodulation in aging $\mathrm{p} 4^{+} \mathrm{T}_{\mathrm{M}}$ (Supplemental Table 4). Corresponding analyses of KLR gene products conducted with polyclonal aging $\mathrm{D}^{\mathrm{b}} \mathrm{NP}_{396}{ }^{+} \mathrm{CD} 8^{+} \mathrm{T}_{\mathrm{M}}$ demonstrated an excellent correlation between the temporal regulation of mRNA (p14 chimera system) and protein (B6 system) expression: while some KLR genes were not translated (Klra8 and Klre1), the levels of other KLR proteins declined significantly with advancing age; only Klrk1 deviated from this pattern due to stable expression by practically all specific $\mathrm{CD} 8^{+} \mathrm{T}_{\mathrm{M}}$ (Figure $4 \mathrm{~A}$ and Supplemental Table 4).

The global decline of KLR gene and protein expression is noteworthy since it stands in apparent contrast with the notion that elevated expression of human

ry components, and TLRs (Supplemental Table 2). Of particular prominence were IL- 6 , IL-10, and TGF- $\beta$ signaling pathways, all of which have been implicated in the regulation of $\mathrm{CD} 8^{+} \mathrm{T}$ cell immunity under conditions of chronic LCMV infection (25-27), and we note the potential relevance of altered Wnt $/ \beta$-catenin signaling, a pathway that promotes the generation of $\mathrm{CD} 8^{+}$stem cell memory $\mathrm{T}$ cells $\left(\mathrm{CD}^{+} \mathrm{T}_{\mathrm{SCM}}\right)$ (28) (Supplemental Table 2). Lastly, higher order network analyses revealed 16 networks containing at least 10 focus molecules, a moderate degree of connectivity, and predominant signature functions of cell death, cell-to-cell signaling/interactions, and cellular movement (Supplemental Table 3). Thus, the process of aging introduced a series of substantial and diverse molecular changes into a clonotypic $\mathrm{CD} 8^{+} \mathrm{T}_{\mathrm{M}}$ population that collectively point towards altered phenotypic and functional traits that may directly shape evolving aspects of $\mathrm{CD}^{+} \mathrm{T}_{\mathrm{M}}$ homeostasis and $\mathrm{II}^{\circ}$ reactivity.

Coordinated regulation of related gene and protein expression by aging $C D 8^{+} T_{M}$ : the C-type lectins. Based on the parallel observations of progressive phenotypic and molecular $C D 8^{+} \mathrm{T}_{\mathrm{M}}$ conversion processes, we initiated a systematic survey of corresponding gene and protein expression dynamics. Focusing at first on a subset of genes exhibiting a particularly pronounced expression decline ( $>5$-fold downregulation in old vs. young $\mathrm{p} 14^{+} \mathrm{T}_{\mathrm{M}}$ ), we found that nearly half of these transcripts (11 of 24) coded for cell surface receptors/ligands, and that approximately half of the latter molecules
KLR and KIR (functional ortholog of the murine KLR subset of Ly49 genes) proteins is a hallmark of presenescent and senescent $\mathrm{T}$ cells in aged populations (9). To reconcile these discrepancies, we determined KLR expression by aging $\mathrm{CD} 8^{+} \mathrm{T}$ cells of undefined specificity in unmanipulated B6 mice. In confirmation and extension of previous reports (29), we observed a gradual acquisition of $\mathrm{KLR}^{+}$phenotypes, with some receptors (Klrc1, Klrd1, and Klrk1) eventually expressed by more than $50 \%$ of old $\mathrm{CD} 8^{+} \mathrm{T}$ cells (Supplemental Figure 3). The fact that aging $\mathrm{CD} 8^{+} \mathrm{T}$ cells at large are subject to progressive alterations that are diametrically opposed to those observed for virus-specific $C D 8^{+} \mathrm{T}_{\mathrm{M}}$ emphasizes the importance of analytical $\mathrm{CD} 8^{+} \mathrm{T}$ cell-subset differentiation, and if enhanced $\mathrm{T}$ cell-expressed KLRs are considered an indicator for possible senescence, the steady loss of $\mathrm{KLR}^{+}$phenotypes by aging antiviral $C D 8^{+} \mathrm{T}_{\mathrm{M}}$ may be viewed as a reversal thereof.

In light of the good correspondence between mRNA and protein expression data, we extended our analyses to the entire family of C-type lectins including the prominent members $C d 62 l$ and $C d 69$ (Figure 4B, Supplemental Figure 4, and Supplemental Table 4). As expected (12), CD62L expression by aging $\mathrm{CD}^{+} \mathrm{T}_{\mathrm{M}}$ increased substantially, but the abundance and subtle rise of $C d 69$ mRNA was unexpected since CD69 protein is not detectable in resting splenic $\mathrm{CD}^{+} \mathrm{T}_{\mathrm{M}}$ populations (Figure $4 \mathrm{~B}$ ). Rather, $\mathrm{CD} 69$ expression is a hallmark of tissue-resident $\mathrm{CD}^{+} \mathrm{T}_{\mathrm{M}}$ and LN-populating subsets, where it contributes to the limitation of $\mathrm{T}$ cell 
A
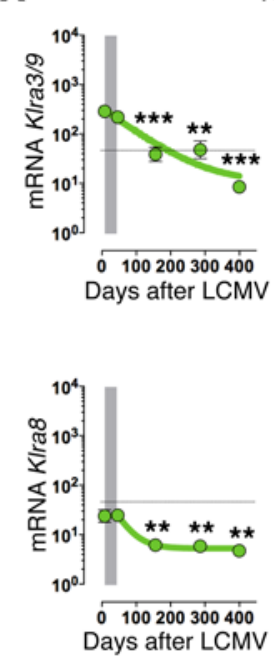

KLRA3/9 (Ly49C/l)

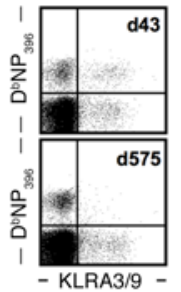

KLRA8 (Ly49H)

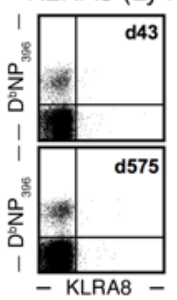

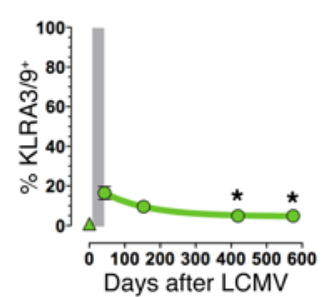

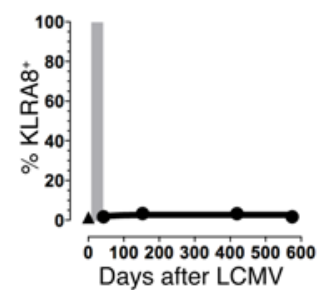

KLRB1C (NK1.1) \& KLRB1F
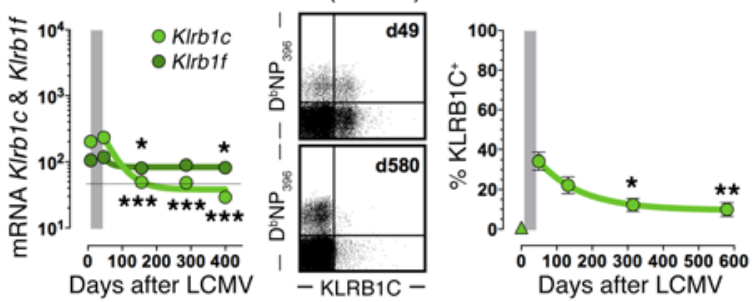

KLRC1/2/3 (NKG2ACE) \& KLRC1 (NKG2A ${ }^{\text {B6}}$ )
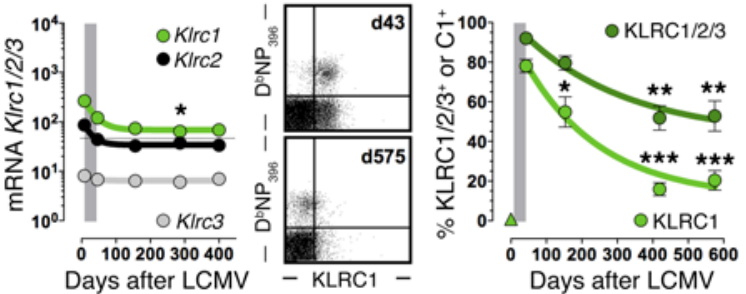

B

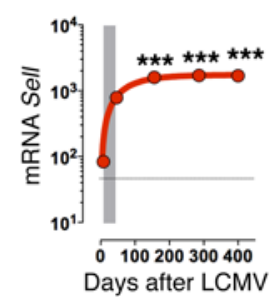

CD62L (L-selectin)

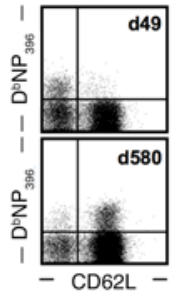

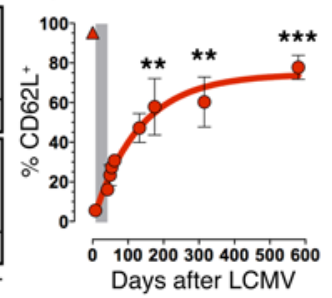

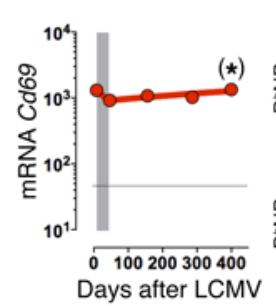

KLRD1 (CD94)
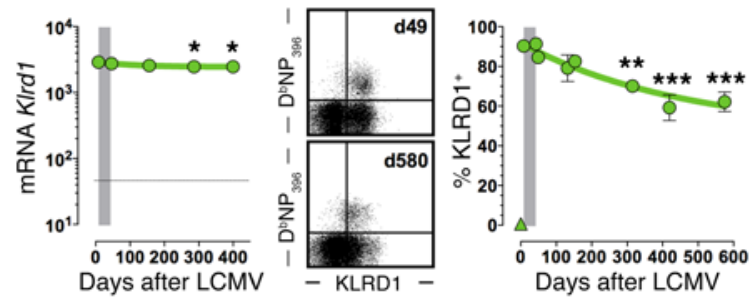

KLRE1 (NKG2I)
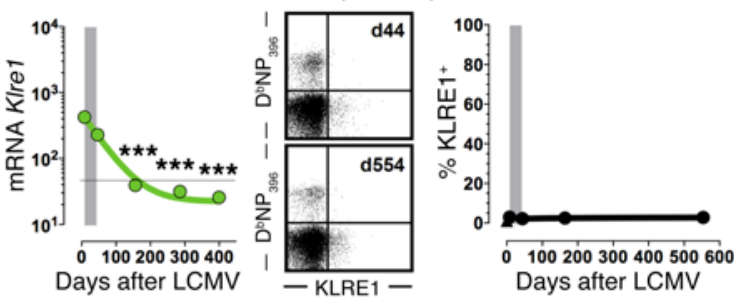

KLRG1
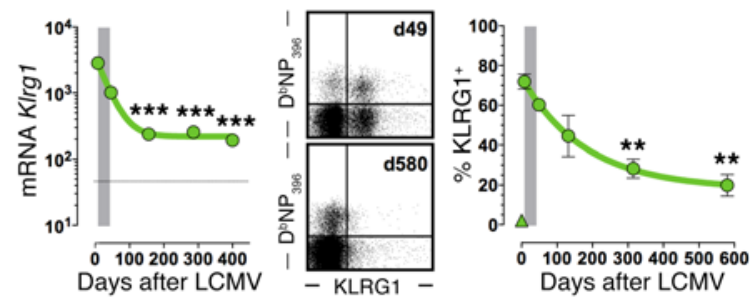

KLRK1 (NKG2D)
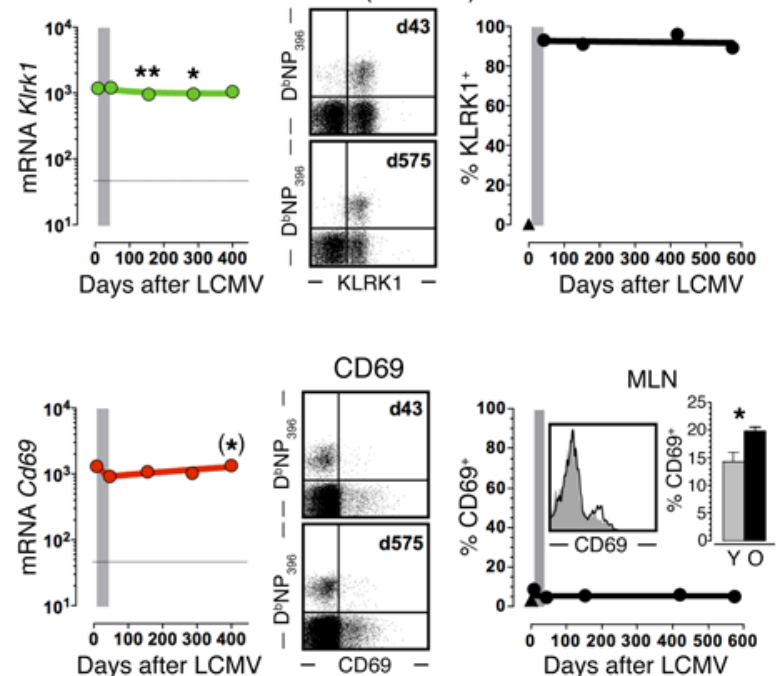

Figure 4. Temporal regulation of C-type lectin expression by virus-specific $\mathbf{C D 8}^{+} \mathbf{T}_{\mathrm{E} / \mathrm{M}}$ The figure is organized into modules consisting of 3 panels each: left, mRNA expression ( $\mathrm{p} 14^{+} \mathrm{T}_{\mathrm{E} / \mathrm{M}}$ microarrays); middle, representative dot plots of young (top) and old (bottom) splenic CD8 ${ }^{+} \mathrm{T}$ cells unless indicated otherwise; right, temporal regulation of $\mathrm{D}^{\mathrm{b} N \mathrm{NP}_{396}}{ }^{+} \mathrm{CD} 8^{+} \mathrm{T}_{\mathrm{E} / \mathrm{M}}$ properties. The gray bars demarcate the transition from $\mathrm{T}_{\mathrm{E}}$ to early $\mathrm{T}_{\mathrm{M}}$ stage (day 42 ), and the triangle symbols refer to $\mathrm{CD} 44^{\circ} \mathrm{CD} 8^{+}$ $\mathrm{T}_{\mathrm{N}}$. All values are the mean \pm 1 SEM with $n \geq 3$ individual mice per time point; ${ }^{*} P<0.05,{ }^{* *} P<0.01$, and ${ }^{* * *} P<0.001$ comparing young and older ( $>$ day 100 ) p14 ${ }^{*}$ $\mathrm{T}_{\mathrm{M}}$ or $\mathrm{D}^{\mathrm{b}} \mathrm{NP}_{396}{ }^{+} \mathrm{CD}^{+} \mathrm{T}_{\mathrm{M}}$, respectively, using 1-way ANOVA. Significant differences emerging during the memory phase are highlighted in red (upregulation) or green (downregulation). This outline also serves as a template for Supplemental Figures 4-14 and the data are further summarized and expanded to related genes in Supplemental Table 4. (A) Temporal regulation of KLR expression. (B) Temporal regulation of CD62L and CD69 expression. (*) indicates statistical significance determined by Student's $t$ test rather than ANOVA. The insert in the CD69 module depicts young (gray, day 67) and old (black, day 725 ) $D^{\text {b }} \mathrm{NP}_{396}{ }^{+}{ }{ }^{2} 8^{+} \mathrm{T}_{\mathrm{M}}{ }$ recovered from MLNs and a corresponding data summary (Y, day 66; O, day 563). MLN insert bar diagram analysis in (B) determined by Student's $t$ test.

egress (30). Notably, the fraction of LCMV-specific CD $69^{+} \mathrm{CD} 8^{+}$ $\mathrm{T}_{\mathrm{M}}$ isolated from LNs was slightly elevated among aged populations (Figure 4B), perhaps a contributing factor to altered trafficking patterns of aged $\mathrm{CD} 8^{+} \mathrm{T}_{\mathrm{M}}(\mathrm{JE}, \mathrm{BD}$, and $\mathrm{DH}$, unpublished observations). Expression of 3 additional gene products (CD72b/c, CD93, and CD205) was minimal or absent, and mRNA species for the remaining C-type and other lectins were mostly maintained at stable levels (Supplemental Figure 4 and Supplemental Table 4). 

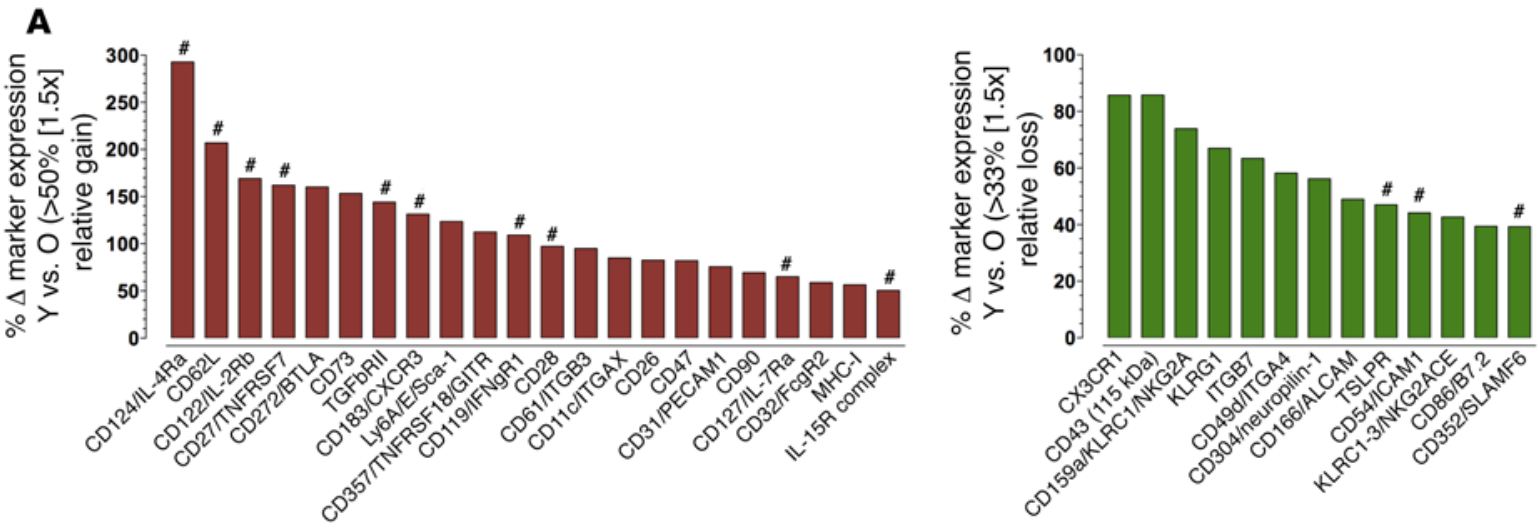

B

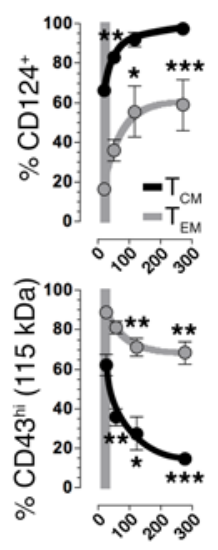

$\mathrm{D}^{\mathrm{DN}} \mathrm{P}_{396}{ }^{+} \mathrm{CD} 8^{+} \mathrm{T}_{\mathrm{CM}}$ and $\mathrm{T}_{\mathrm{EM}}$
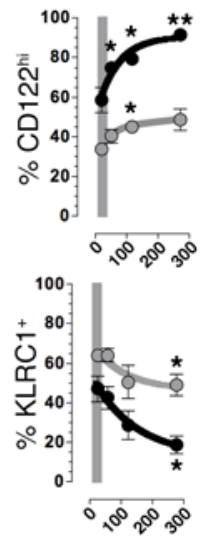

Days after LCMV

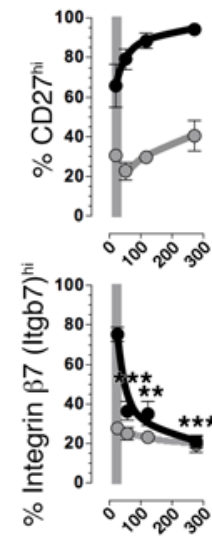

C

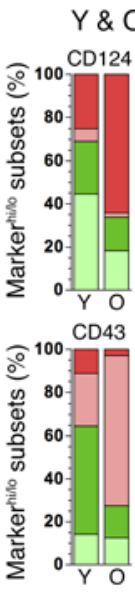

$\mathrm{O} \mathrm{D}^{\mathrm{b} N \mathrm{NP}_{396}}{ }^{+} \mathrm{CD}^{+} \mathrm{T}_{\mathrm{M}}$

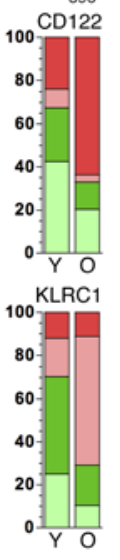

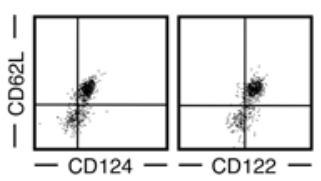
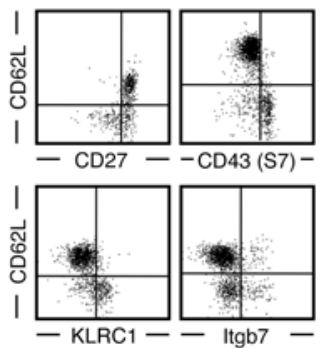

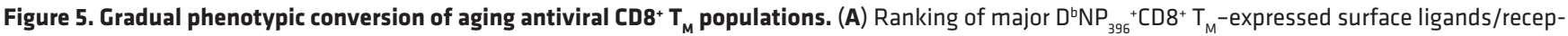
tors according to differential expression between young (6-7 weeks) and old ( $>80$ weeks) populations; primary expression data for all markers are found in Figure 4 and Supplemental Figures 2 and 4-14. Inclusion criteria for present ranking: differential expression observed in $>25 \%$ of $D^{\mathrm{b}} \mathrm{NP}_{396}{ }^{+} \mathrm{CD} 8^{+} \mathrm{T}_{\mathrm{M}}$ as well as > 1.5-fold up- or downregulation; \#, molecular pathways interrogated in related work (JE, BD, and DH, unpublished observation). (B) Phenotypic

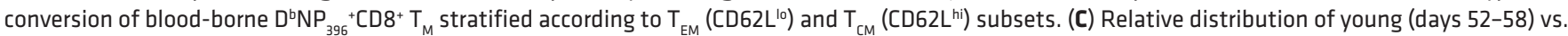

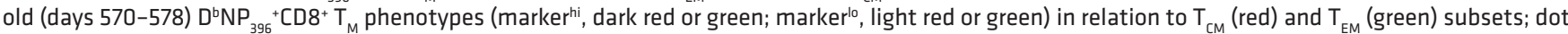
plots gated on aged $D^{b} \mathrm{NP}_{396}{ }^{+} \mathrm{CD}^{+} \mathrm{T}_{\mathrm{M}}$; data generated with $n \geq 3$ mice/group in multiple independent experiments. ${ }^{*} P<0.05,{ }^{* *} P<0.01$, and ${ }^{* * *} P<0.001$ by 1 way ANOVA. Y, young; 0 , old.

Molecular and phenotypic remodeling of aging antiviral CD8 ${ }^{+}$ $T_{M}$ : beyond the $T_{E M} / T_{C M}$ paradigm. Using a similar approach to gene selection and ontology as employed above, we allocated $\sim 25 \%$ of DEGs in Supplemental Table 1 to 30 structural or functional families that were subsequently investigated for the presence and temporal regulation of all known family members. With an emphasis on surface receptors/ligands, survival/apoptosis, effector activities, and signaling, we analyzed $\sim 1,570$ genes, $\sim 520$ of which were expressed by aging $\mathrm{p} 14^{+} \mathrm{T}_{\mathrm{M}}$. In the course of the extended memory phase ( $\mathrm{d} 46-\mathrm{d} 400)$, more than one third of expressed genes exhibited a significant increase or decrease, and for greater than $80 \%$ of these DEGs the changes constituted a continuation of dynamic adaptations already discernible in the transition from effector memory $\left(\mathrm{T}_{\mathrm{EM}}\right)$ to early memory stage (Figure 4, Supplemental Table 4, and Supplemental Figure 4-14). The pronounced molecular reconfiguration evident during the relatively brief contraction phase of $\mathrm{p} 14^{+} \mathrm{T}_{\mathrm{E}}$ largely confirmed previous observations (31); similarly, the slower transcriptomic alterations accrued by aging $\mathrm{p} 14^{+} \mathrm{T}_{\mathrm{M}}$ corresponded remarkably well to the molecular differences very recently reported for early and late $\mathrm{p} 14^{+}$central memory $\mathrm{T}$ cells $\left(\mathrm{p} 14^{+} \mathrm{T}_{\mathrm{CM}}\right)(17)$. However, our observation that the dynamic signatures of aging $\mathrm{p}^{+} 4_{\mathrm{M}} \mathrm{T}_{\mathrm{M}}$ exhibited a prominent and slowly fading echo of these changes indicates that the continued molecular remodeling of $\mathrm{p} 14^{+} \mathrm{T}_{\mathrm{M}}$ is a fundamental property associated with $\mathrm{CD}^{+} \mathrm{T}_{\mathrm{M}}$ longevity.

To correlate the molecular evolution of $\mathrm{p} 14^{+} \mathrm{T}_{\mathrm{M}}$ with temporal alterations at the protein level, we evaluated expression of $\sim 140$ cell surface antigens by $\mathrm{D}^{\mathrm{b}} \mathrm{NP}_{396}{ }^{+} \mathrm{CD}^{+} \mathrm{T}_{\mathrm{M}}$ in aging LCMV-immune B6 mice (Figure 4, Supplemental Table 4, and Supplemental Figures 2 and 4-14); note that these analyses also included antigens not differentially expressed at the mRNA level, and were expanded in some cases to other LCMV-specific $\mathrm{CD}^{+} \mathrm{T}_{\mathrm{M}}$ subsets (not shown). Although expression levels of the various phenotypic markers expectedly differed substantially, $\sim 80 \%$ of all antigens analyzed were present on specific $\mathrm{CD}^{+} \mathrm{T}_{\mathrm{M}}$ subsets, and of these, $\sim 65 \%$ were progressively increased or decreased in a statistically signif- 
A Functional avidities

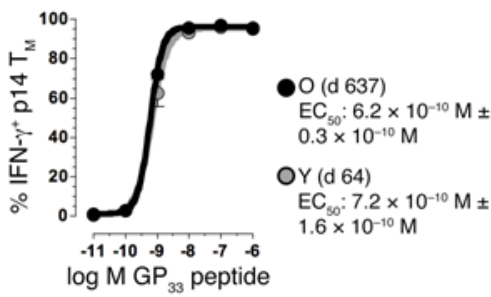

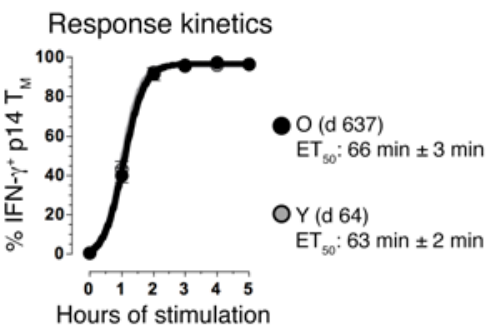

D

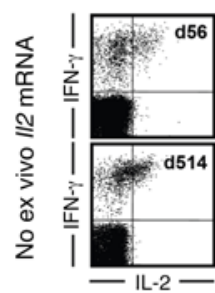

IL-2

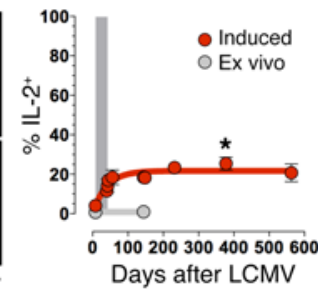

IL-3
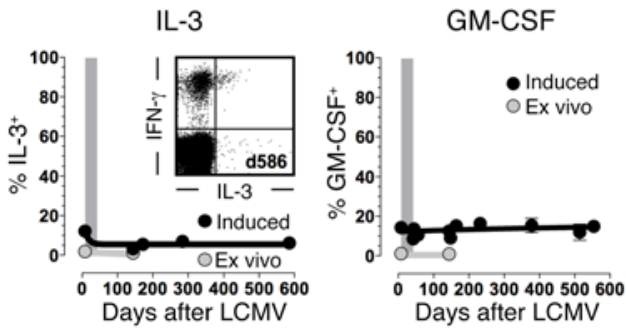

$\mathrm{IL}-10$
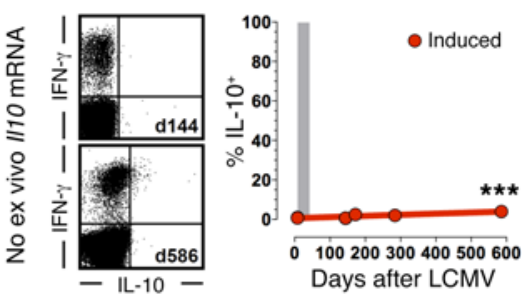

E XCL1 (lymphotactin)

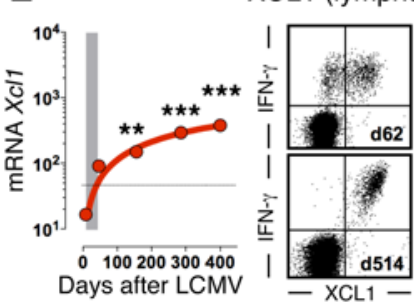

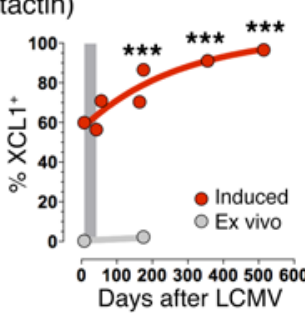

Figure 6. Evolving functionalities of aging antiviral CD8 $^{+} \mathbf{T}_{M}$ : cytokines, TNFSFs, chemokines. (A) Functional avidities (EC $C_{50}$ values) and response kinetics ( $E T_{50}$ values) were calculated by plotting the fraction of IFN- $\gamma^{+}$p14 $^{+} \mathrm{T}_{\mathrm{M}}$ as a function of $\mathrm{GP}_{33}$ peptide concentration (5-hour stimulation) or stimulation time ( $\left(0^{-6} \mathrm{M}\right.$ peptide) and nonlinear regression analysis. (B-E) Temporal regulation of IFN- $\gamma$, TNFSF, cytokine, and chemokine mRNA (p14+ $\mathrm{T}_{\mathrm{E} / \mathrm{M}}$, microarray data, ex vivo) as well as protein expression ( $\mathrm{NP}_{396}$-specific $\mathrm{CD8}{ }^{+} \mathrm{T}_{\mathrm{E} / \mathrm{M}}$, ex vivo [gray] and induced [black/red]); panels are organized in modules as detailed in Figure 4, dot plots are gated on $\mathrm{NP}_{396}$ peptide-stimulated $\mathrm{CD} 8^{+} \mathrm{T}$ cells. ${ }^{*} P<0.05$, ${ }^{* *} P<0.01$, and ${ }^{* * *} P<0.001$ by 1 -way ANOVA and asterisks indicate statistical differences between young ( days 42-65) and older $\mathrm{CD}^{+} \mathrm{T}_{\mathrm{M}}$. Note that the amount of induced IFN- $\gamma$ and CD4OL content (geometric mean fluorescence intensity values) rather than percentage of IFN- $\gamma$ - or CD4OL-producing CD8 ${ }^{+} T_{M}$ increased with age; data generated with $n \geq 3$ mice/group in multiple independent experiments.

icant manner. Adding another $\sim 10 \%$ of cell surface antigens that exhibited discernible yet nonsignificant trends towards altered expression levels, we conclude that $\sim 75 \%$ of phenotypic $\mathrm{CD}^{+} \mathrm{T}_{\mathrm{M}}$ markers, many of which have been implicated in the active regula- tion of immune responses (32), are subject to continued modulation during the long-term maintenance of $\mathrm{T}$ cell memory (a rankordered listing of major differentially expressed surface receptors/ligands is displayed in Figure $5 \mathrm{~A})$. Of further importance is 
the apparent translational regulation captured in our phenotypic analyses: for several surface receptors/ligands subject to particularly pronounced expression changes in aging $C D 8^{+} T_{M}$ (Figure $5 \mathrm{~A})$, corresponding mRNA levels did not significantly change over time (TGF $\beta$-RII [Supplemental Figure 6], glucocorticoid-induced TNFR family-related gene [GITR; Supplemental Figure 7], CD28 [Supplemental Figure 8], CD31, CD32, CD47 [Supplemental Figure 10, A and B], CD49d, CD61, integrin $\beta_{7}$ [Supplemental Figure 11], CXCR3 [Supplemental Figure 12A], CD26, and Ly6A [Supplemental Figure 13, A and B]); in an unusual case we even found divergent gene and protein regulation (CD11c; Supplemental Figure 11). These observations underscore the importance of complementary molecular and phenotypic analyses for an inclusive characterization of $\mathrm{CD}^{+} \mathrm{T}_{\mathrm{M}}$ aging.

Collectively, our findings suggest that phenotypic conversion rather than stability constitutes a hallmark of specific CD8 ${ }^{+}$ $\mathrm{T}$ cell memory, and also may provide an adjusted perspective on the popular $\mathrm{T}_{\mathrm{EM}} / \mathrm{T}_{\mathrm{CM}}$ paradigm (33): our longitudinal analyses of respective CD62 $\mathrm{L}^{\mathrm{lo}} \mathrm{CD} 62 \mathrm{~L}^{\text {hi }}$ subsets (Figure $5 \mathrm{~B}$ ) corroborate the observation that both populations accrue phenotypic changes over time and that in turn align with their respectively increasing recall potentials $(14,17)$. As a net result of these interrelated maturation dynamics, $\mathrm{T}_{\mathrm{CM}}$ exhibiting cardinal properties of aged $\mathrm{CD}^{+}$ $\mathrm{T}_{\mathrm{M}}$ (e.g., CD $124^{+} \mathrm{CD} 122^{\text {hi }} \mathrm{CD} 27^{\text {hi }} \mathrm{CD} 43^{\text {lo }} \mathrm{KLRC1}$-integrin $\beta_{7}^{\text {lo }}$ ) eventually come to dominate the pool of aging LCMV-specific CD8 ${ }^{+} \mathrm{T}_{\mathrm{M}}$ (Figure 5C). Here, the expanded context of dynamic expression patterns largely (albeit not completely) shared by CD62L and multiple other surface receptors/ligands supports the general utility of $\mathrm{T}_{\mathrm{EM}} / \mathrm{T}_{\mathrm{CM}}$ distinction, but also reveals the essentially arbitrary and limiting nature of CD62L expression levels as denominators for major $\mathrm{CD}^{+} \mathrm{T}_{\mathrm{M}}$ subsets.

Evolving functionalities of aging antiviral $C D 8^{+} T_{M}$. The expedient elaboration of various effector activities by specific $C D 8^{+} \mathrm{T}_{M}$ constitutes a cardinal component of immune protection, yet the extent to which age-associated adaptations may alter kinetics, quantity, and/or quality of $C D 8^{+} \mathrm{T}_{\mathrm{M}}$ functions remain incompletely defined. Using induced IFN- $\gamma$ production as a principal readout, young and old $\mathrm{p} 14^{+} \mathrm{T}_{\mathrm{M}}$ exhibited identical functional avidities and response kinetics and thus a complete preservation of determinants that shape the rapid $\mathrm{CD} 8^{+} \mathrm{T}_{\mathrm{M}}$ response to cognate antigens (Figure 6A). The amount of $\mathrm{CD}^{+} \mathrm{T}_{\mathrm{M}}$-produced IFN- $\gamma$, however, increased with age, suggesting that older $\mathrm{CD}^{+} \mathrm{T}_{\mathrm{M}}$ may become more potent $\mathrm{II}^{\circ} \mathrm{CD}^{+} \mathrm{T}_{\mathrm{E}}$ (Figure $6 \mathrm{~B}$ ). To assess this possibility at large, we first defined the spectrum of young $\mathrm{CD}^{+} \mathrm{T}_{\mathrm{M}}$ activities by quantifying constitutive and TCR-induced expression of $\sim 200$ $\mathrm{p} 14^{+} \mathrm{T}_{\mathrm{M}}$ genes comprising perforin/granzymes, interferons, cytokines/chemokines, TNF superfamily (TNFSF), TGF- $\beta S F$, PDGF, and MMP members (Supplemental Figure 15 and data not shown). Then, for $\sim 90 \%$ of transcripts demonstrating a significant TCRinduced upregulation, we analyzed corresponding protein expression in aging LCMV-immune B6 mice. Overall, we observed a strict conservation of $\mathrm{CD} 8^{+} \mathrm{T}_{\mathrm{M}}$ functionalities (inducible TNF- $\alpha$, GM-CSF, IL-3, and chemokine [CCL1, -3, -4, -5] production) in the absence of obvious immune deviation by aged $\mathrm{CD}^{+} \mathrm{T}_{\mathrm{M}}$ (no acquisition of rapid IL-4, IL-13, IL-17A, IL-21, TGF- $\beta$, or TNFSF1b, -3, -7, $-8,-9,-10,-11$ production capacity; Figure $6, \mathrm{C}$ and D, Supplemental Table 4, and data not shown).
Five additional effector functions, however, improved over time, including a growing proportion of $\mathrm{CD}^{+} \mathrm{T}_{\mathrm{M}}$ capable of induced FasL expression, a modest increase of IL-2 production potential as shown previously $(12,17)$, and a more pronounced augmentation of inducible XCL1 chemokine synthesis (Figure 6, C-E). At the single-cell level, aging $\mathrm{CD}^{+} \mathrm{T}_{\mathrm{M}}$ also made more CD40L and a very small subset acquired the capacity to produce IL-10 (Figure 6, C and D), perhaps through enhanced IL-27 responsiveness as a consequence of their increasing CD130 (also known as IL-6 signal transducer) expression (Supplemental Figure 6A); the limited IL-10 production capacity of aged $\mathrm{CD}^{+} \mathrm{T}_{\mathrm{M}}$, however, was lost upon rechallenge since all blood-borne and splenic $\mathrm{II}^{\circ} \mathrm{CD} 8^{+} \mathrm{T}_{\mathrm{E}}$ failed to synthesize IL-10 (data not shown). In summary, aging of $\mathrm{CD}^{+} \mathrm{T}_{\mathrm{M}}$ confers enhanced functionality, and although autocrine IL-2 production can promote $\mathrm{II}^{\circ} \mathrm{CD} 8^{+} \mathrm{T}_{\mathrm{E}}$ expansions (34), it apparently combines with other functional gains to advance more effective pathogen control (JE, BD, and $\mathrm{DH}$, unpublished observations).

Lastly, granule exocytosis is central to the cytolytic activity of $\mathrm{CD}^{+} \mathrm{T}_{\mathrm{E}}$ and presumably also $\mathrm{CD} 8^{+} \mathrm{T}_{\mathrm{M}}$, although diverging temporal expression patterns of components within this pathway and limited knowledge about their precise contribution to in vivo $\mathrm{CD}^{+} \mathrm{T}_{\mathrm{M}}$ killing (35) complicate any predictions about evolving $\mathrm{CD}^{+} \mathrm{T}_{\mathrm{M}}$ cytotoxic $\mathrm{T}$ lymphocyte (CTL) functions. For example, several relevant mRNA species are downregulated in aging $\mathrm{p} 14^{+}$ $\mathrm{T}_{\mathrm{M}}$ (Supplemental Figure 15, A and B) and the precipitous decline of Gzma message constitutes the most pronounced molecular difference between young and old $\mathrm{p} 14^{+} \mathrm{T}_{\mathrm{M}}$ (Table 1 and Figure 7A). Corresponding protein expression analyses demonstrated ex vivo-detectable GZMA in a major $\mathrm{CD}^{+} \mathrm{T}_{\mathrm{E}}$ subset but also revealed, in contrast with the rapid downregulation of GZMB (12, 24), an attenuated decline that resulted in complete GZMA loss only $\sim 1$ year after infection (Figure 7A), a pattern similar to that of human $\mathrm{CD}^{+} \mathrm{T}_{\mathrm{M}}$ analyzed after smallpox vaccination (36). Further evidence for a possible reduction of cytotoxic $\mathrm{CD}^{+} \mathrm{T}_{\mathrm{M}}$ function may be derived from the marked decline of $C D 8^{+} \mathrm{T}_{M}$-expressed CX3CR1 (Table 1 and Figure 5A), a chemokine receptor that phenotypically (though not functionally) correlates with $C D 8^{+} \mathrm{T}_{\mathrm{M}} \mathrm{CTL}$ potential (37). On the other hand, we noted a subtle trend among mRNA expression patterns shared by several genes associated with $\mathrm{CD} 8^{+} \mathrm{T}_{\mathrm{E} / \mathrm{M}}$ effector functions but not evident in other gene families: after a slight (Ifng, Prfl, Tnf) or more prominent (Gzmb) $\mathrm{k} / \mathrm{m}, \mathrm{Ccl} 3 / 4, \mathrm{~S} 1 \mathrm{pr} 5$ ) decline of message that lasted $\sim 5$ months, mRNA levels began to steadily rise again (Figures $6 \mathrm{~B}$ and $7 \mathrm{~A}$, Supplemental Figure 15A, Supplemental Figure 12B, and data not shown). In addition, aging $\mathrm{CD}^{+} \mathrm{T}_{\mathrm{M}}$ exhibited a small increase in degranulation capacity (Figure 7B).

To ascertain how these expression patterns are integrated into actual killing capacity, we conducted an in vivo CTL assay (35) with young and old LCMV-immune mice. As shown in Figure 7C, young $\mathrm{CD}^{+} \mathrm{T}_{\mathrm{M}}$ exhibited faster and more pronounced early CTL activity, but by 6 hours both young and old $\mathrm{CD}^{+} \mathrm{T}_{\mathrm{M}}$ eliminated the majority $(\geq 80 \%)$ of target cells in the spleen. In a modified assay employing AT of both $\mathrm{CD}^{+} \mathrm{T}_{\mathrm{M}}$ and targets into naive recipients to achieve an in vivo effector:target (E:T) ratio of 1:1 (38), CTL functions of young and old CD8 ${ }^{+} \mathrm{T}_{\mathrm{M}}$ proved indistinguishable (Figure 7D). Therefore, aging $\mathrm{CD}^{+} \mathrm{T}_{\mathrm{M}}$, in spite of decreasing killing kinetics, largely preserve their capacity for effective target cell destruc- 
A

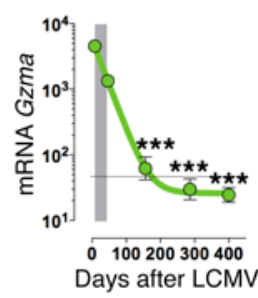

Granzyme A

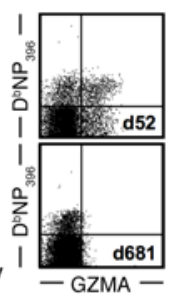

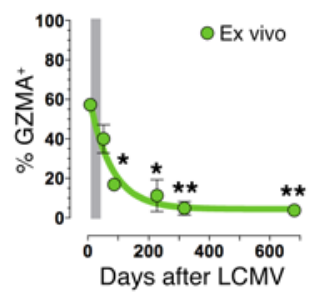

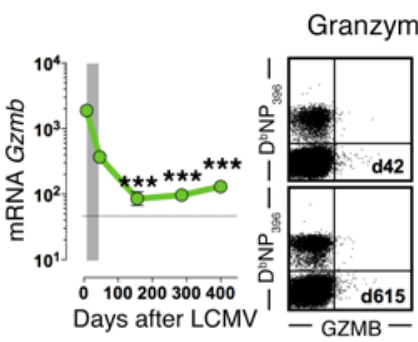

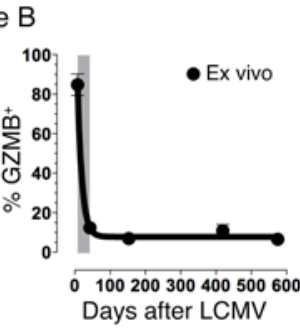

B

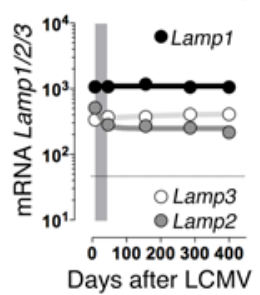

Degranulation (CD107 assay)

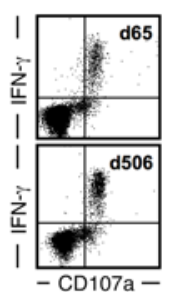

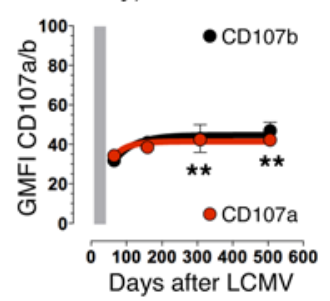

D $\mathrm{CD}^{+} \mathrm{T}_{\mathrm{M}}$ killing $(6 \mathrm{~h} ; \mathrm{E}: \mathrm{T}=1: 1)$

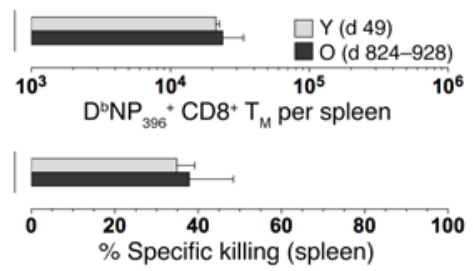

C

$\mathrm{CD}^{+} \mathrm{T}_{\mathrm{M}}$ and assay principle
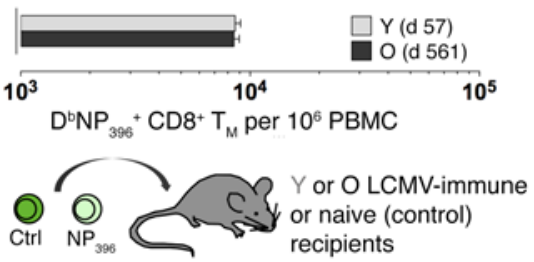

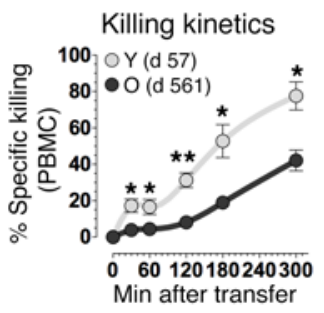

Blood-borne targets

$(5 \mathrm{~h})$

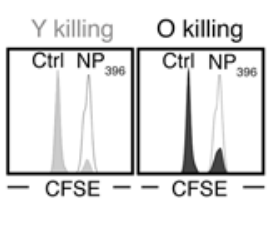

$\mathrm{CD}^{+} \mathrm{T}_{\mathrm{M}}$ killing $(6 \mathrm{~h})$

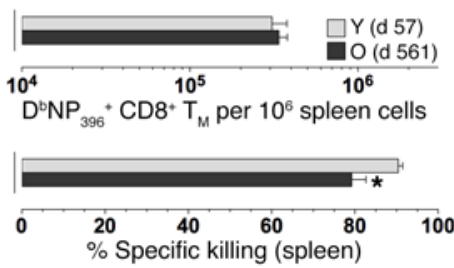

Figure 7. Evolving functionalities of aging antiviral $\mathrm{CD8}^{+} \mathbf{T}_{\mathrm{M}}$ : granzymes, degranulation, and CTL activity. (A) Temporal regulation of granzyme mRNA $\left(\mathrm{p} 14^{+} \mathrm{T}_{\mathrm{E} / \mathrm{M}}\right.$, microarray data) and protein $\left(\mathrm{D}^{\mathrm{b} N \mathrm{~N}_{396}}{ }^{+} \mathrm{CD} 8^{+} \mathrm{T}_{\mathrm{E} / \mathrm{M}}\right.$ ) expression analyzed directly ex vivo. (B) Lamp1, -2 , and -3 mRNA expression and degranulation capacity of aging $\mathrm{p} 14^{+} \mathrm{T}_{E / M}$ and $\mathrm{NP}_{396}$-specific CD8 ${ }^{+} \mathrm{T}_{\mathrm{M}}$, respectively. (C) Left, young $(\mathrm{Y})$ and old (O) LCMV-immune mice harboring identical numbers of blood-borne $C D 8^{+} T_{M}$ were used to assess $C D 8^{+} T_{M} C T L$ activities in vivo; middle, killing kinetics determined in blood after AT of $4.5 \times 10^{6}$ differentially CFSE-labeled control and $\mathrm{NP}_{396}$ peptide-coated target cells each (histograms gated on target cells retrieved 5 hours after AT into LCMV-immune [young, gray; old, black] or naive [open] mice); right, splenic $D^{b} \mathrm{NP}_{396}{ }^{+} \mathrm{CD}^{+} \mathrm{T}_{\mathrm{M}}$ numbers at conclusion of assay and extent of specific killing. (D) $D^{\mathrm{b} N P_{396}}{ }^{+} \mathrm{CD}^{+} \mathrm{T}_{\mathrm{M}}$

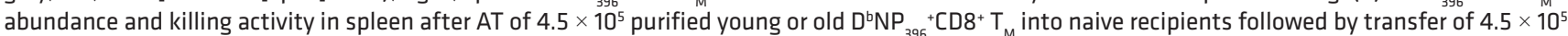
sensitized and control target cells each; data generated with $n \geq 3$ mice/group in multiple independent experiments. ${ }^{*} P<0.05$, ${ }^{*} P<0.01$, and ${ }^{* * *} P<0.001$ by 1 -way ANOVA or Student's $t$ test. PBMC, peripheral blood mononuclear cells.

tion. We also note that target killing by $\mathrm{CD}^{+} \mathrm{T}_{\mathrm{M}}$ appears to proceed according to a sigmoidal association (Figure 7C) rather than the exponential association observed for $\mathrm{CD}^{+} \mathrm{T}_{\mathrm{E}}$ (35), suggesting that $\mathrm{CD}^{+} \mathrm{T}_{\mathrm{M}}$ CTLs may be less reliant on immediate cytotoxicity as conferred, for example, by perforin release from $\mathrm{CD}^{+} \mathrm{T}_{\mathrm{E}}(38)$.

Accelerating the maturation process of $C D 8^{+} T_{M}$ : p14-titration chimeras. A notable feature of the extended $\mathrm{CD}^{+} \mathrm{T}_{\mathrm{M}}$ conversion process is its prolonged yet asynchronous nature (Figure 4, Supplemental Figure 2, and Supplemental Figures 4-14); i.e., the pace and extent of conversion is distinct for different gene products and thus likely contributes to the great phenotypic variety among $\mathrm{CD}^{+} \mathrm{T}_{\mathrm{M}}$ populations (1). The origins of phenotypic heterogeneity are rooted in the earliest stages of the $\mathrm{T}$ cell response, since diverse $C D 8^{+} \mathrm{T}_{\mathrm{E}}$ populations can be derived from a single naive $\mathrm{CD}^{+} \mathrm{T}$ cell, possibly through asymmetric division but certainly as a consequence of distinct priming interactions and division histories (39). That the degree of pathogen replication, accompanying inflammation, and effective pathogen elimination decisively shape $C D 8^{+} T_{E}$ differentiation is further documented in multiple studies employing chimeras generated with titrated numbers of TCRtg CD8 ${ }^{+} \mathrm{T}_{\mathrm{N}}$ as well as their transfer at different times after pathogen challenge and/or experimental reduction of attendant inflammation or antigen presentation. Importantly, an increase of TCRtg $\mathrm{CD}^{+} \mathrm{T}_{\mathrm{N}}$ input numbers and/or decrease of inflammation/ antigen presentation can accelerate $\mathrm{CD}^{+} \mathrm{T}_{\mathrm{M}}$ generation as determined by expansion/contraction kinetics, $C D 8^{+} \mathrm{T}_{\mathrm{M}}$ cellularity, and/or limited phenotypic and functional analyses (2, 40-43).

Here, we revisited these concepts with an expanded focus on the kinetics of progressive $\mathrm{CD} 8^{+} \mathrm{T}_{\mathrm{M}}$ maturation and associated in vivo functionalities as a consequence of their early ontogeny; i.e., we constructed p14 chimeras with graded numbers of $\mathrm{p} 14^{+} \mathrm{T}_{\mathrm{N}}\left(2 \times 10^{2}\right.$ to $2 \times 10^{5}$, referred to as $\mathrm{p} 14^{2 \mathrm{e} 2}-\mathrm{p} 14^{2 \mathrm{ee}}$ chimeras $)$ to determine the relative speed with which subsequently established $\mathrm{p} 14^{+} \mathrm{T}_{\mathrm{M}}$ populations would acquire properties resembling endogenously generated aged $\mathrm{CD}^{+} \mathrm{T}_{\mathrm{M}}$. In most tissues, initial numerical expansion of $\mathrm{I}^{\circ} \mathrm{p} 14^{+} \mathrm{T}_{\mathrm{E}}$ does not occur until $\sim 72$ hours after LCMV challenge, but proliferation starts somewhat earlier in the MedLNs $(19,21)$. Enumerating $\mathrm{p}^{1} 4^{+} \mathrm{T}_{\mathrm{E}}$ in the MedLNs on day 3 or 4 after infection, we found that their expansions in $\mathrm{p} 14^{2 \mathrm{e} 2}-\mathrm{p} 14^{2 \mathrm{e} 5}$ chimeras tracked exactly with original $\mathrm{p} 14^{+} \mathrm{T}_{\mathrm{N}}$ input numbers, indicating that the early kinetics of $\mathrm{p} 14^{+} \mathrm{T}_{\mathrm{E}}$ population growth are largely impervious to $\mathrm{p} 14^{+} \mathrm{T}_{\mathrm{N}}$ precursor number (Fig- 

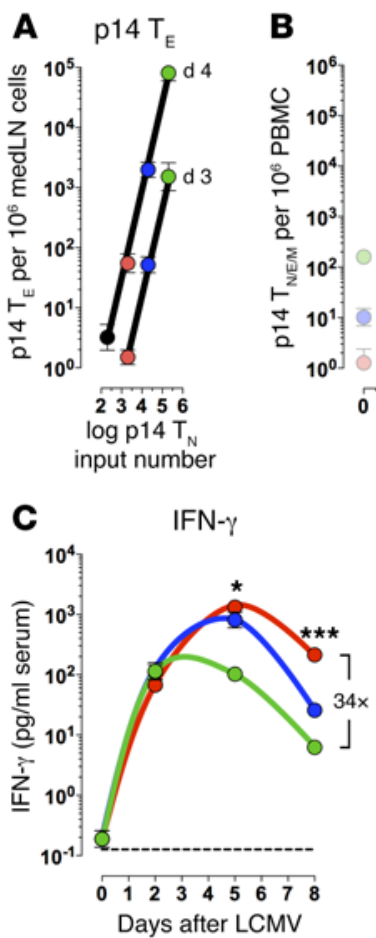

B
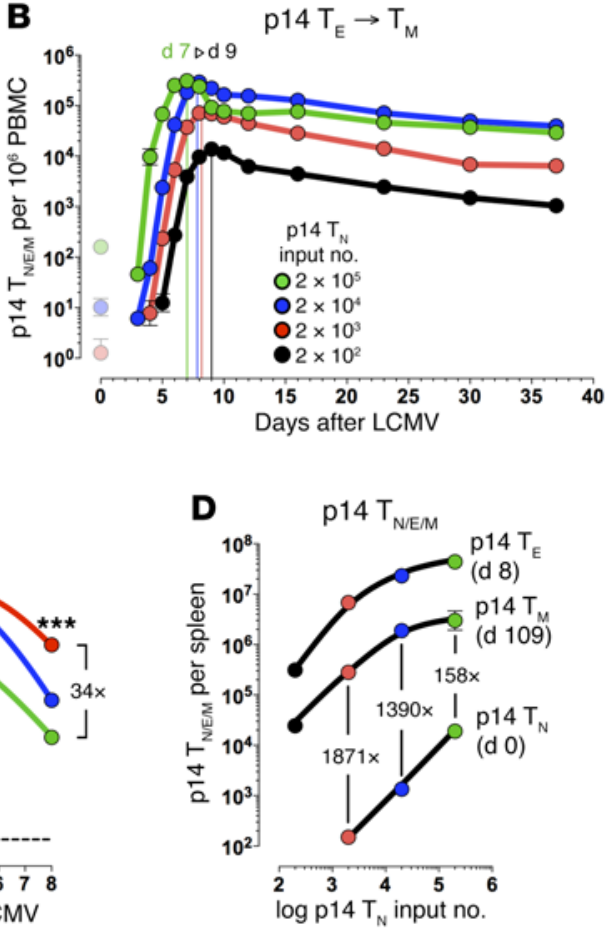

$\mathbf{F}$
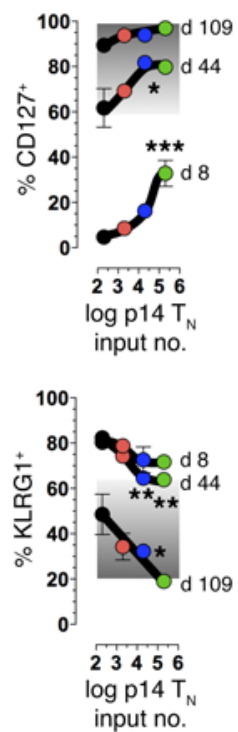

G

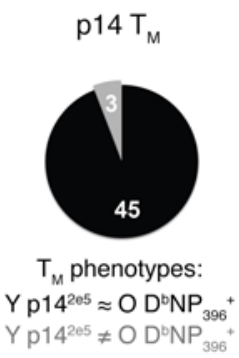

p14 $\mathrm{T}_{\mathrm{M}}$ phenotypes
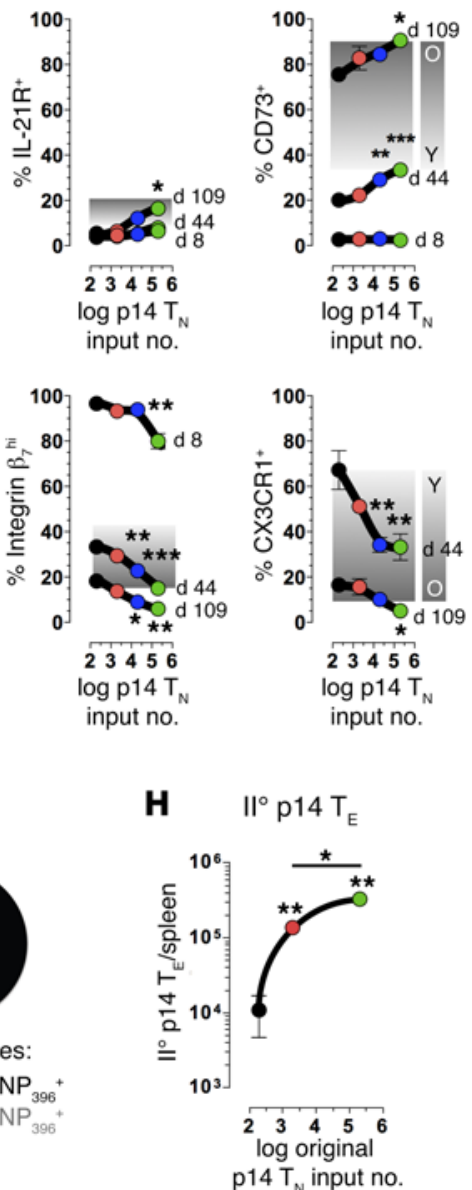

Figure 8. Accelerating the maturation process of $\mathbf{C D 8}^{+} \mathbf{T}_{M}$ : $\mathbf{p}$ 14-titration chimeras. (A) Chimeras were constructed with graded $p 14^{+} T_{N}$ numbers $\left(2 \times 10^{2}\right.$ to $2 \times 10^{5}$; color legend in panel $B$ ), and $p 14^{+} T_{E}$ expansions were quantified in the MedLNs on days 3-4 (connected data points, respectively). (B) Kinetics of p14+ $T_{E}$ expansion/contraction and $p 14^{+} T_{M}$ development in blood ( 5 combined experiments; $n=3-6$ ); data for day 0 indicate p14+ $T_{N}$ retrieved in the absence of infection, and vertical colored lines indicate respective $p 14^{+} T_{E}$ peak expansions. (C) Serum IFN- $\gamma$ as a function of p14 ${ }^{+} T_{N}$ input number. (D) Absolute numbers of transferred p14+ $T_{N}$ (day 0), $T_{E}$ (day 8) and $T_{M}$ (day 109) in spleen; values indicate fold difference between p14+ $T_{N}$ and $T_{M}$ cellularity. (E) CD127 and CX3CR1 expression by splenic p14 $T_{E / M}$ recovered from respective chimeras on days 8, 44, and 109. (F) Kinetics of phenotypic p14 ${ }^{+} T_{E / M}$ differentiation as function of $p 14^{+} T_{N}$ precursor frequency. Analyses of splenic p14+ $T_{E}$ (day 8) and $T_{M}$ (days 44 and 109) were conducted as above; data points from

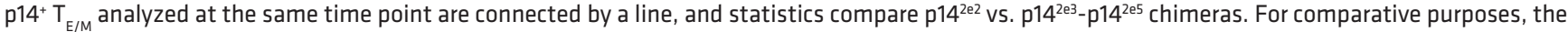
graded background shading demarcates the spread of respective marker expression from young ( $Y$, light) to old ( 0 , dark) $D^{\mathrm{b}} \mathrm{NP}_{395}{ }^{+} \mathrm{CD} 8^{+} \mathrm{T}_{M}$ in $\mathrm{B} 6$ mice $($ Figure 4 and Supplemental Figures 5-14). (C) Summary of preceding analyses comprising 48 markers categorized according to similarity between p14+ $T_{M}$ from young p14 $2{ }^{2 e 5}$ chimeras ( 7 weeks) and old $D^{b} \mathrm{NP}_{396}{ }^{+} \mathrm{CD} 8^{+} \mathrm{T}_{\mathrm{M}}$ ( $\geq 80$ weeks). (H) AT/rechallenge experiments were performed with $2 \times 10^{3} \mathrm{p} 14^{+} \mathrm{T}_{\mathrm{M}}$ purified from respective p14-titration chimeras infected $\sim 7$ weeks earlier, AT, LCMV Armstrong challenge and quantification of $I I^{\circ}$ p $14^{+} \mathrm{T}_{\mathrm{E}}$ expansions 8 days later $(n=3$; representative of 3 similar experiments). ${ }^{*} P<0.05,{ }^{* *} P<0.01$, and ${ }^{* *} P<0.001$ by 1 -way ANOVA or Student's $t$ test.

ure $8 \mathrm{~A})$. We next monitored the dynamics of the $\mathrm{p} 14^{+} \mathrm{T}_{\mathrm{E}}$ response in peripheral blood. Following LCMV challenge and an initial drop of blood-borne $\mathrm{p} 14^{+} \mathrm{T}$ cells similar to that reported for other tissues (19) (and also observed for aged $\mathrm{II}^{\circ} \mathrm{p} 14^{+} \mathrm{T}_{\mathrm{E}}$ in peripheral blood; Figure $1 \mathrm{~F}$ ), p14 ${ }^{+} \mathrm{T}_{\mathrm{E}}$ started to expand after more than 72 hours and, consistent with the early $\mathrm{p}^{+} 4^{+} \mathrm{T}_{\mathrm{E}}$ expansion kinetics in the MedLNs, further analysis of population dynamics throughout the $\mathrm{I}^{\circ}$ response revealed no significant differences among respective population growth rates (Figure $8 \mathrm{~B})$. As expected $(2,40)$, an increase of $\mathrm{p} 14^{+} \mathrm{T}_{\mathrm{N}}$ numbers both enhanced and expedited the peak expansions of $\mathrm{p} 14^{+} \mathrm{T}_{\mathrm{E}}$ (from $\mathrm{d} 9$ in $\mathrm{p} 14^{2 \mathrm{e} 2}$ to $\mathrm{d} 7$ in $\mathrm{p} 14^{2 \mathrm{e} 5}$ chimeras) (Figure $8 \mathrm{~B}$ ), but we note that a 1,000 -fold difference in $\mathrm{p} 14^{+}$ $\mathrm{T}_{\mathrm{N}}$ input numbers produced an only 23 -fold difference between respective $\mathrm{p}^{+} 4^{+} \mathrm{T}_{\mathrm{E}}$ burst sizes on $\mathrm{d} 7-\mathrm{d} 9$ (Figure $8 \mathrm{~B}$ ). Thus, higher numbers of naive precursors restrain the $\mathrm{I}^{\circ}$ response by earlier termination of proliferative $\mathrm{CD} 8^{+} \mathrm{T}_{\mathrm{E}}$ expansion and corresponding curbing of the relative burst size.

Nevertheless, greater $\mathrm{p} 14^{+} \mathrm{T}_{\mathrm{E}}$ expansions in the higher input chimeras exerted better inflammation control at later stages $(\mathrm{d} 5-\mathrm{d} 8)$ of the effector response (Figure 8C), and brought about a correspondingly larger $\mathrm{p} 14^{+} \mathrm{T}_{\mathrm{M}}$ population (Figure $8 \mathrm{D}$ ). A comparison of $\mathrm{p} 14^{2 \mathrm{e} 2}$ versus $\mathrm{p} 14^{2 e 5}$ chimeras, for example, showed that the relative difference between splenic p $14^{+} \mathrm{T}_{\mathrm{E}}$ cellularities ( $\mathrm{d} 8,140$-fold) was largely maintained in the memory phase (d109, 123-fold) (Figure 8D), but these calculations do not take into account the precise timing of $\mathrm{p} 14^{+} \mathrm{T}_{\mathrm{E}}$ peak expansions. We therefore compared the numbers of 

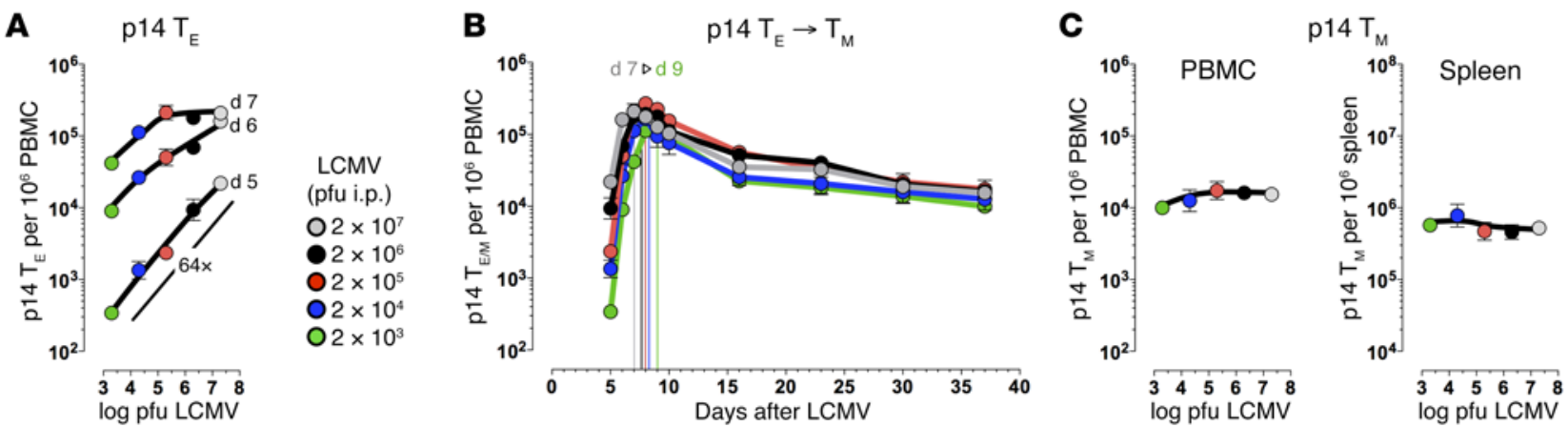

D

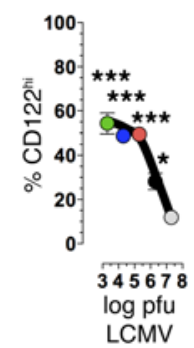

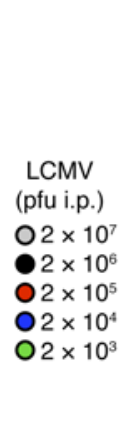

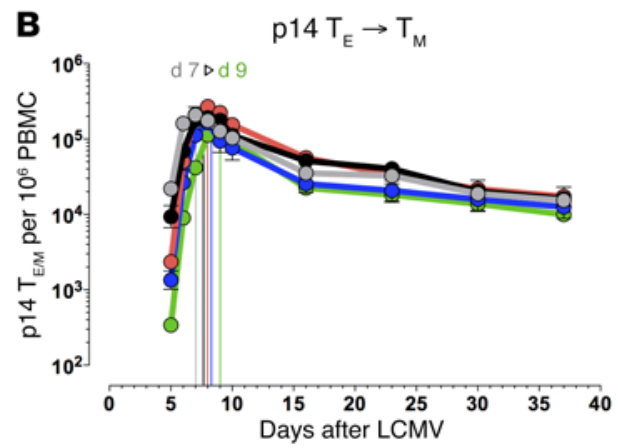

p14 $\mathrm{T}_{\mathrm{M}}$ phenotypes

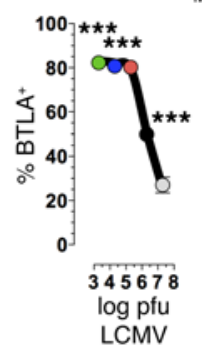

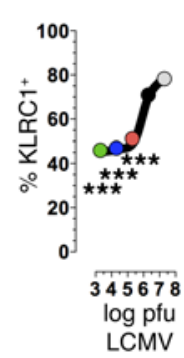

$\mathbf{E}$

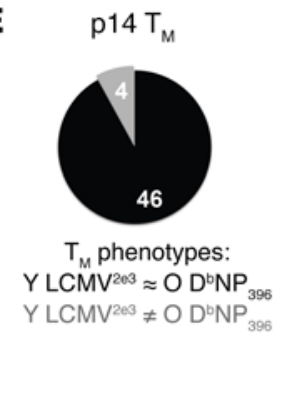

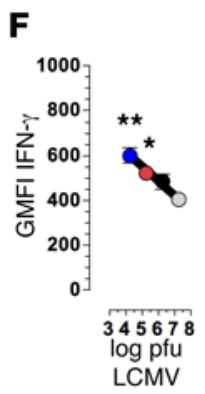
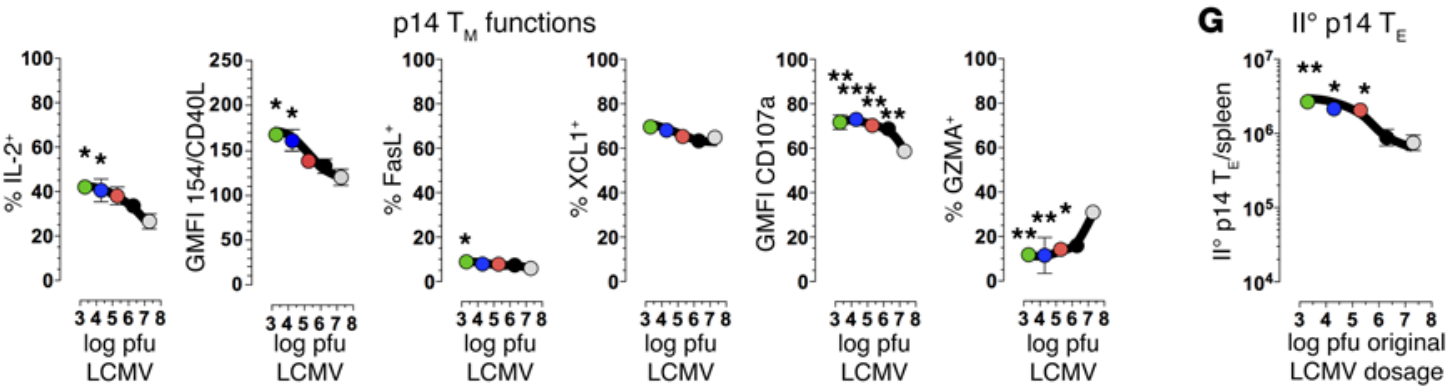

Figure 9. Delaying the maturation process of $\mathrm{CD8}^{+} \mathrm{T}_{\mathrm{M}}$ : virus-titration chimeras. (A) Virus-titration chimeras were constructed with $10^{4} \mathrm{p} 14^{+} T_{N^{\prime}}$ challenged with graded dosages of LCMV Armstrong ( $2 \times 10^{3}$ to $\left.2 \times 10^{7} \mathrm{PFU}\right)$, and early p14+ $T_{E}$ expansions were quantified in blood (days 5-7); note the 64-fold difference $(P=0.006)$ between low-dose $\left(L C M V^{2 e 3}\right)$ and high-dose $\left(L C M{ }^{227}\right)$ virus-titration chimeras on day 5. (B) Kinetics of p14 ${ }^{+} T_{E}$ and $T_{M}$ development in peripheral blood of virus-titration chimeras; vertical colored lines indicate time of respective peak expansions. (C) p14 ${ }^{+} T_{M}$ numbers in blood (day 37 ) and spleen (day 42). (D) Relative kinetics of phenotypic p14+ $\mathrm{T}_{\mathrm{M}}$ differentiation as a function of virus challenge dosage were determined on days $42-49$; data are displayed as in Figure $8 \mathrm{~F}$, and statistics compare $\mathrm{p}^{1} 4^{+} \mathrm{T}_{M}$ properties of high-dose $\left(2 \times 10^{7} \mathrm{PFU}\right)$ vs. lower dose $\left(\leq 2 \times 10^{6} \mathrm{PFU}\right)$ virus-titration chimeras. (E) Pie chart summary of preceding analyses comprising 50 markers stratified according to similarity between young p14 ${ }^{+} T_{M}$ recovered from LCMV ${ }^{2 e 3}$ virus-

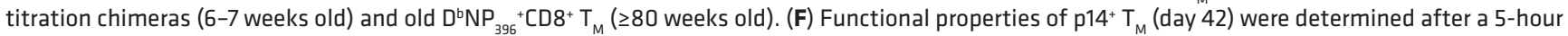
peptide stimulation (IFN- $\gamma$, IL-2, CD40L, FasL, XCL1, CD107a), or directly ex vivo (CZMA). (C) AT/rechallenge experiments were performed with $2 \times 10^{3}$ p14 ${ }^{+}$ $T_{M}$ purified from virus-titration chimeras (day 42) and $I^{\circ}$ p $14^{+} T_{E}$ expansion analyses on day 8. All summary data obtained with $n \geq 3$ mice/group in multiple independent experiments. ${ }^{*} P<0.05,{ }^{*} P<0.01$, and ${ }^{* *} P<0.001$ by 1 -way ANOVA. PBMC, peripheral blood mononuclear cells.

splenic $\mathrm{p} 14^{+} \mathrm{T}_{\mathrm{N}}$ retrieved in the absence of infection with $\mathrm{p} 14^{+} \mathrm{T}_{\mathrm{M}}$ (d109) and calculated that $\mathrm{p} 14^{2 \mathrm{ee}}$ chimeras generated a $\mathrm{p} 14^{+} \mathrm{T}_{\mathrm{M}}$ pool that was 158 -fold greater than the starting population; $14^{2 e 3}$ chimeras, in contrast, produced a 1,871-fold bigger $\mathrm{p} 14^{+} \mathrm{T}_{\mathrm{M}}$ compartment (Figure $8 \mathrm{D}$ ). We conclude that the relative extent to which clonal expansion populates the subsequent $\mathrm{CD}^{+} \mathrm{T}_{\mathrm{M}}$ compartment is curtailed by higher $\mathrm{CD} 8^{+} \mathrm{T}_{\mathrm{N}}$ frequencies, likely through restricted $\mathrm{CD} 8^{+}$ $\mathrm{T}_{\mathrm{E}}$ differentiation that favors accelerated $\mathrm{CD} 8^{+} \mathrm{T}_{\mathrm{M}}$ development (2).

To assess the extent of phenotypic $\mathrm{CD}^{+} \mathrm{T}_{\mathrm{M}}$ alterations acquired as a function of increasing $\mathrm{p} 14^{+} \mathrm{T}_{\mathrm{N}}$ input numbers, we first evaluated the regulation of IL-7Ra/CD127 expression. As shown previously (2), re-expression of CD127 by p14 $4^{+} \mathrm{T}_{\mathrm{E}}$ and $\mathrm{T}_{\mathrm{M}}$ proceeded with kinetics proportional to the numbers of available p14 ${ }^{+} \mathrm{T}_{\mathrm{N}}$, but by $\sim 3$ months after challenge, practically all $\mathrm{p} 14^{+} \mathrm{T}_{\mathrm{M}}$, irrespective of $\mathrm{p} 14^{+} \mathrm{T}_{\mathrm{N}}$ precursor frequency, expressed high levels of CD127; conversely, downmodulation of $\mathrm{p} 14^{+} \mathrm{T}_{\mathrm{M}}$-expressed CX3CR1 was progressively delayed by limiting $\mathrm{p} 14^{+} \mathrm{T}_{\mathrm{N}}$ input numbers (Figure $8 \mathrm{E}$ ). Although a similar experimental modulation of $\mathrm{CD}^{+} \mathrm{T}_{\mathrm{M}}$ maturation kinetics has been demonstrated for additional surface receptors/ligands $(2,17)$, the actual extent of phenotypic alterations in this experimental scenario remains unknown. Our comprehensive characterization of $\mathrm{p} 14^{2 \mathrm{e} 2}-\mathrm{p} 14^{2 \mathrm{e} 5}$ chimeras now reveals a striking correlation between $\mathrm{p} 14^{+} \mathrm{T}_{\mathrm{N}}$ precursor frequencies and multiple dozens of $14^{+} \mathrm{T}_{\mathrm{M}}$ phenotypes: for $\sim 94 \%$ of markers analyzed (45 of 48), an increase of $\mathrm{p} 14^{+} \mathrm{T}_{\mathrm{N}}$ accelerated the conversion towards an aged $\mathrm{CD}^{+} \mathrm{T}_{\mathrm{M}}$ phenotype, a pattern that 
A

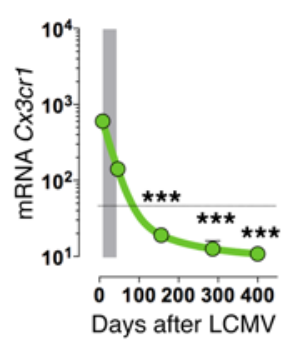

CX3CR1 (fractalkine receptor)

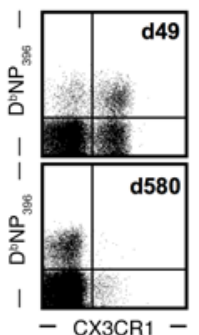

B

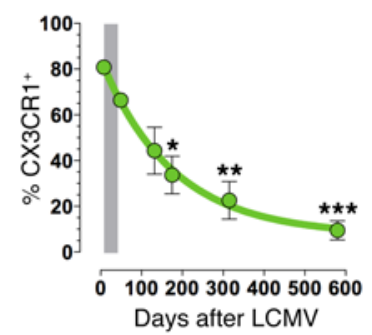

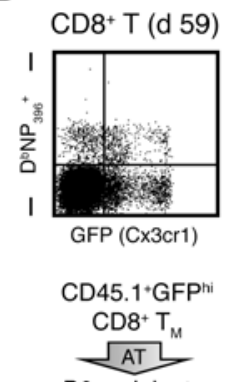

$B 6$ recipients

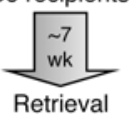

CD4/45R-GFP ${ }^{h}$ (post-sort)

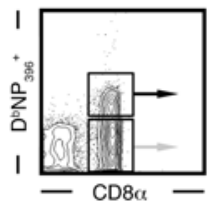

CD45.1 ${ }^{+} \mathrm{CD}^{+} \mathrm{T}$

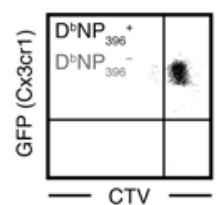

CD45.1 ${ }^{+} \mathrm{CD}^{+} \mathrm{T} \quad \mathrm{CD} 45.1^{+} \mathrm{CD}^{+} \mathrm{T}$

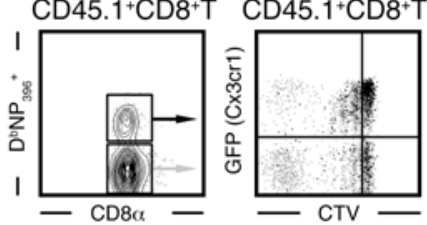

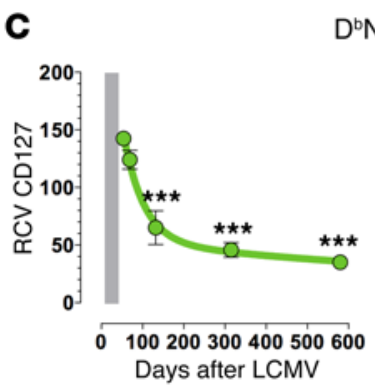

$\mathrm{D}^{\mathrm{b} N \mathrm{~N}_{396}}{ }^{+} \mathrm{CD}^{+} \mathrm{T}_{\mathrm{M}}$

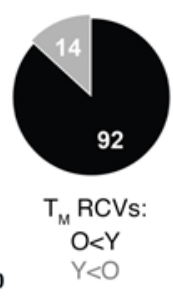

Days after LCMV
D

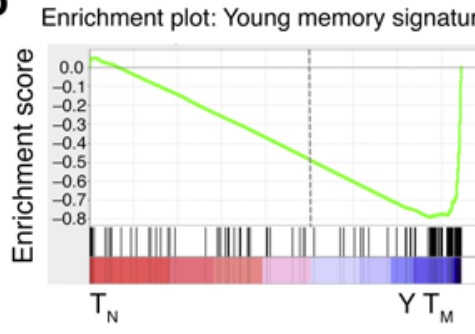

Enrichment plot: Old memory signature

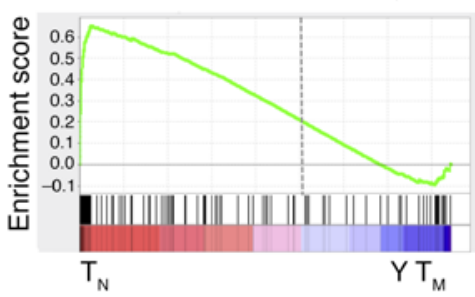

$\mathbf{F}$

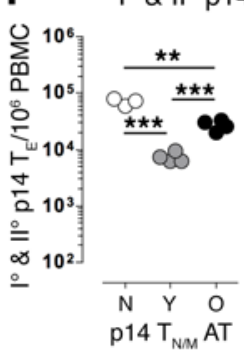

E

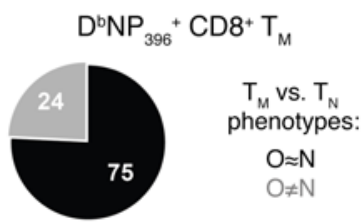

Figure 10. Progressive conversion of aging virus-specific $\mathrm{CDB}^{+} \mathbf{T}_{\mathrm{M}}$ : towards homogeneity and naiveté. (A) Temporal regulation of $C x 3 \mathrm{cr} 1 \mathrm{mRNA}$ and protein expression. (B) Top, splenic CD8 ${ }^{+}$T cells from LCMV-immune $C x 3 C r 7^{+/ C f p}$ mice were analyzed for GFP expression, or loaded with CellTrace Violet (see Supplemental Methods for more information) and sorted according to GFPhi status; bottom, experimental outline and properties of retrieved CD8 ${ }^{+} \mathrm{T}$ cells. (C) Progressive acquisition of more homogeneous $C D 8^{+} T_{M}$ phenotypes as determined by declining RCV values; the pie chart summarizes RCV analyses of 106 markers expressed by young (6-7 weeks old) and old ( $>80$ weeks old) $D^{b} \mathrm{NP}_{396}{ }^{+} C D 8^{+} T_{M}$. O, old; $\mathrm{Y}$, young (D) The top 180 genes overexpressed by young or old $14^{+} T_{M}$ (signatures) were investigated by GSEA using datasets for polyclonal CD8 ${ }^{+} T_{N}\left(T_{N}\right.$ ) and LCMV-CP ${ }_{33}-$ specific CD8 $^{+} T_{M}$ (day $30\left[Y T_{M}\right]$ ) (see Supplemental Figure 18); note respective enrichments of young $p 14^{+} T_{M}$ signatures in $Y T_{M}$ and old $p 14^{+} T_{M}$ in $T_{N}(P<0.0001)$. (E) Expression of 99 markers was compared between aging $D^{b} N P_{396}{ }^{+} C D 8^{+} T_{M}$ and $C D 8^{+} T_{N}$, and categorized according to similarity $\left(0 \approx N\right.$, conversion towards $C D 8^{+} T_{N}$ phenotypes; $0 \neq N$, contrasting expression). (F) AT/rechallenge experiments conducted with $2 \times 10^{3}$ purified $\mathrm{p} 14^{+} \mathrm{T}_{\mathrm{N}}$ or young $/ \mathrm{old} \mathrm{T}_{\mathrm{M}}$, and analyzed for $\mathrm{I}^{\circ}(\mathrm{N})$ and $\mathrm{II}^{\circ}(\mathrm{Y}$ vs. 0$) \mathrm{p} 14^{+} \mathrm{T}_{\mathrm{E}}$ expansions in blood (day 7.5) and spleen (day 8). ${ }^{*} P<0.05$, ${ }^{*} P<0.01$, and ${ }^{* *} P<0.001$ by 1 -way ANOVA. PBMC, peripheral blood mononuclear cells.

often became discernible already at the $\mathrm{T}_{\mathrm{E}}$ stage (Figure 8, $\mathrm{F}$ and G). Perhaps most importantly, the relative preponderance of aged p14 ${ }^{+} \mathrm{T}_{\mathrm{M}}$ phenotypes in the higher input chimeras also correlated with improved $\mathrm{II}^{\circ} \mathrm{p} 14^{+} \mathrm{T}_{\mathrm{E}}$ reactivities (Figure $8 \mathrm{H}$ ).

Delaying the maturation process of $C D 8^{+} T_{M}$ : virus-titration chimeras. If the above contentions are correct, $\mathrm{CD} 8^{+} \mathrm{T}_{\mathrm{M}}$ maturation at large should also be amenable to modulation under conditions of fixed $\mathrm{CD}^{+} \mathrm{T}_{\mathrm{N}}$ precursor frequencies, i.e., by experimental variation of the viral burden and degree of inflammation. We therefore challenged p14 chimeras harboring identical numbers of $\mathrm{p} 14^{+} \mathrm{T}_{\mathrm{N}}$ with graded dosages of LCMV ranging across 4 orders of magnitude. Interestingly, the kinetics of $\mathrm{I}^{\circ} \mathrm{p} 14^{+} \mathrm{T}_{\mathrm{E}}$ expansion and $\mathrm{p} 14^{+}$ $\mathrm{T}_{\mathrm{M}}$ generation in these virus-titration chimeras were distinctly different from those in the p14-titration chimeras: an escalation of the virus challenge dose accelerated the timing of $\mathrm{p} 14^{+} \mathrm{T}_{\mathrm{E}}$ peak expansions $\left(2 \times 10^{3} \mathrm{PFU}\right.$ on $\mathrm{d} 9$ vs. $2 \times 10^{7} \mathrm{PFU}$ on $\left.\mathrm{d} 7\right)$, yet neither respective burst sizes nor contraction kinetics or $\mathrm{p}^{+} 4^{+} \mathrm{T}_{\mathrm{M}}$ numbers were greatly affected by the different infection protocols (Figure $9, \mathrm{~A}-\mathrm{C})$. At the same time, the phenotypic disparity of $\mathrm{p} 14^{+} \mathrm{T}_{\mathrm{M}}$ populations in the virus-titration chimeras was pronounced: for $92 \%$ of cell surface receptors/ligands analyzed (46 of 50), high-dose challenge readily delayed the acquisition of aged $\mathrm{CD}^{+} \mathrm{T}_{\mathrm{M}}$ phenotypes (Figure 9, D and E; expression patterns of 49 individual markers are shown in Supplemental Figure 16). Thus, the population growth rates of $\mathrm{I}^{\circ} \mathrm{CD} 8^{+} \mathrm{T}_{\mathrm{E}}$ directly determine the kinetics of subsequent phenotypic $\mathrm{CD} 8^{+} \mathrm{T}_{\mathrm{M}}$ maturation.

This conclusion is further supported by an analysis of $\mathrm{p} 14^{+}$ $\mathrm{T}_{M}$ effector activities. An increase of LCMV inoculation dosage depressed inducible $\mathrm{p}^{+} 4^{+} \mathrm{T}_{\mathrm{M}}$ functions (IFN- $\gamma, \mathrm{IL}-2, \mathrm{CD} 4 \mathrm{OL}$, and degranulation) and also delayed the downmodulation of GZMA (the impact on restrained FasL and XCL1 synthesis was less pronounced, although it followed the same trend), and $\mathrm{p} 14^{+} \mathrm{T}_{\mathrm{M}}$ popu- 


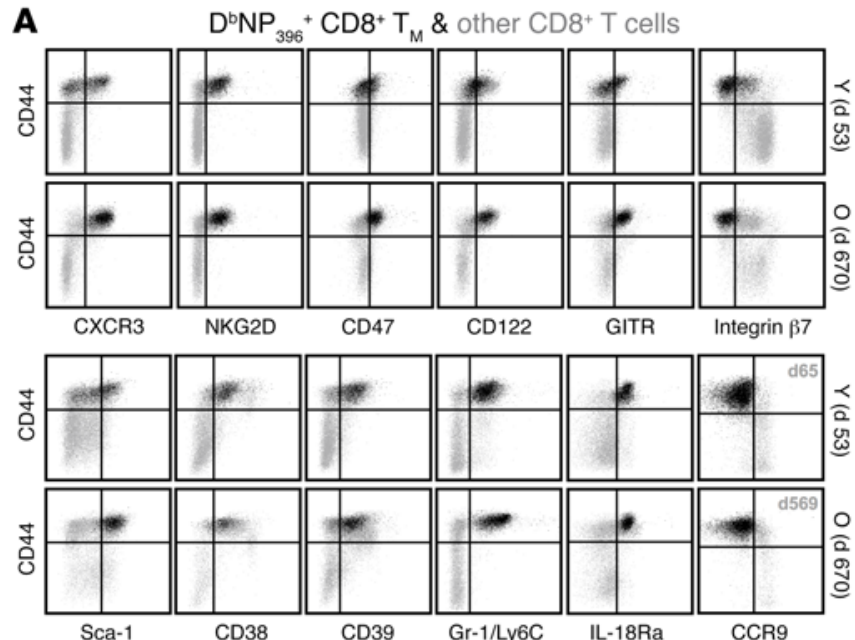

B $\quad \mathrm{K}^{b} \mathrm{VV}-\mathrm{B} 8 \mathrm{R}_{20}{ }^{+} \mathrm{CD} 8^{+} \mathrm{T}_{\mathrm{N}} \& \mathrm{~T}_{\mathrm{VM}}$
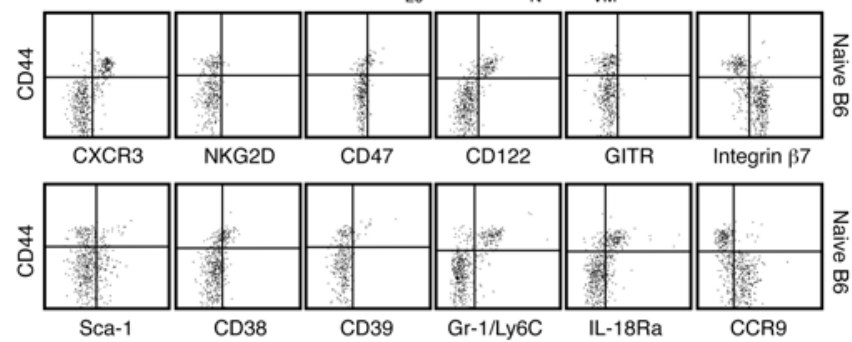

C Integrin $\alpha_{4}(\mathrm{CD} 49 \mathrm{~d})$
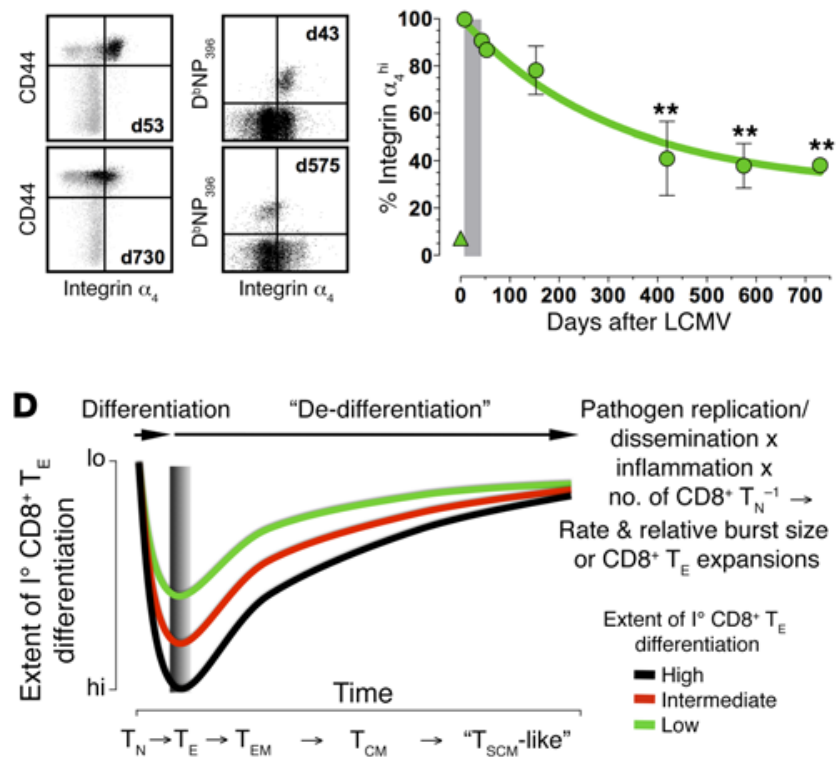

lations with less mature phenotypes and decreased functionalities also exhibited lower $\mathrm{II}^{\circ}$ expansions in vivo (Figure 9, F and G). Taken together, the p14 titration and virus titration experiments demonstrate that $C D 8^{+} \mathrm{T}_{\mathrm{M}}$ maturation in general is precipitated by original priming conditions that restrain $C D 8^{+} \mathrm{T}_{\mathrm{E}}$ differentiation through paced or abortive proliferative expansion (low challenge dosage or high $\mathrm{CD} 8^{+} \mathrm{T}_{\mathrm{N}}$ precursor frequency), reduced inflammation, and/or expedited pathogen control (not shown).

Differential relay of phenotypic and functional properties from $I^{\circ}$ to $I I^{\circ} C D 8^{+} T_{M}$ populations. Superior recall capacities not only
Figure 11. Memory markers old and new: the "rebound model" of $\mathrm{T}_{M}$ maturation. (A) Phenotypic properties of young and old splenic CD8 ${ }^{+} T_{M}$ (CCR9: PBMC d65/d569); dot plots distinguish $D^{b} \mathrm{NP}_{396}{ }^{+} \mathrm{CD}^{+} \mathrm{T}_{M}$ (black) and other $\mathrm{CD}^{+} \mathrm{T}$ cells (gray). (B) Phenotypic properties of virus-specific $\mathrm{CD} 8^{+}$

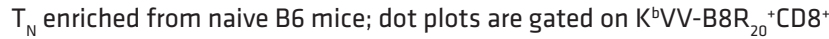
$T_{N}$ with CD44 expression distinguishing genuine $C D 44^{\circ} \mathrm{CD} 8^{+} T_{N}$ and $\mathrm{CD}_{4} 4^{\text {hiCD8 }}{ }^{+} \mathrm{T}_{\mathrm{VM}}$. (C) Kinetics of integrin $\alpha_{4} / \mathrm{CD} 49 \mathrm{~d}$ expression by $\mathrm{D}^{\mathrm{b}} \mathrm{NP}_{396}{ }^{+}$ $\mathrm{CD}^{+} \mathrm{T}_{\mathrm{E} / \mathrm{M}}$. Dot plots are gated on CD8 ${ }^{+} \mathrm{T}$ cells with left-hand plots distinguishing $D^{b} \mathrm{NP}_{396}{ }^{+} \mathrm{CD}^{+} \mathrm{T}_{M}$ (black) from other $\mathrm{CD} 8^{+} \mathrm{T}$ cells (gray); triangle symbol: $C D 44^{\circ}{ }^{\circ} \mathrm{CD} 8^{+} \mathrm{T}_{\mathrm{N}^{*}}$ (D) The "rebound model" of $\mathrm{T}_{\mathrm{M}}$ maturation: kinetics of progressive conversion towards a mature and naive-like CD8 ${ }^{+}$ $T_{M}$ phenotype (dedifferentiation) are accelerated or delayed according to the extent of initial $T_{E}$ differentiation (integrated metric for the product of pathogen replication/dissemination, inflammation and reciprocal CD8 ${ }^{+}$ $T_{N}$ precursor frequency that ultimately determines rate and relative burst size of $C D 8^{+} T_{E}$ expansions). Colored curves refer to $C D 8^{+} T_{E / M}$ populations that proceed through lesser (green), intermediate (red), or advanced (black) stages of $I^{\circ} T_{E}$ differentiation, and the gray-shaded area demarcates the variable timing of peak $C D 8^{+} T_{E}$ expansions according to experimental conditions (earlier, high pathogen challenge dosage/inflammation or CD8 ${ }^{+}$ $T_{N}$ precursor frequencies; later, reduced infection/inflammation or $C D 8^{+} T_{N}$ numbers). ${ }^{* *} P<0.01$ by 1 -way ANOVA.

position $\mathrm{CD}^{+} \mathrm{T}_{\mathrm{M}}$ to exert improved immune protection, but also impinge on the subsequent development of $\mathrm{II}^{\circ} \mathrm{CD} 8^{+} \mathrm{T}$ cell memory (Figure 2, $\mathrm{F}$ and G). To further explore the impact of $\mathrm{I}^{\circ} \mathrm{CD} 8^{+} \mathrm{T}_{\mathrm{M}}$ age on $\mathrm{II}^{\circ} \mathrm{CD}^{+} \mathrm{T}_{\mathrm{M}}$ generation, we conducted contemporaneous analyses 2-3 months after performing original mixed AT/rechallenge experiments and found that $\mathrm{II}^{\circ} \mathrm{CD} 8^{+} \mathrm{T}_{\mathrm{M}}$ derived from old as opposed to young $\mathrm{I}^{\circ} \mathrm{CD} 8^{+} \mathrm{T}_{\mathrm{M}}$ exhibited more mature phenotypes and diversified functional capacities consistent with an overall accelerated reacquisition of aged $\mathrm{CD} 8^{+} \mathrm{T}_{\mathrm{M}}$ features (Supplemental Figure 17, A-D); in addition, these properties directly corresponded with a greater recruitment of old $\mathrm{II}^{\circ} \mathrm{CD}^{+} \mathrm{T}_{\mathrm{M}}$ into a III ${ }^{\circ}$ response (Supplemental Figure 17, A and E). It is noteworthy that the precipitated $\mathrm{II}^{\circ}$ memory formation from aged $\mathrm{I}^{\circ} \mathrm{CD}^{+} \mathrm{T}_{\mathrm{M}}$ proceeds in the wake of larger II $^{\circ}$ expansions (i.e., increased relative burst size) and therefore potentially more pronounced effector differentiation. However, enhanced $\mathrm{II}^{\circ} \mathrm{CD} 8^{+} \mathrm{T}_{\mathrm{E}}$ responses primarily emerge as a consequence of better $\mathrm{II}^{\circ} \mathrm{CD} 8^{+} \mathrm{T}_{\mathrm{E}}$ survival and not their faster or prolonged proliferation (Figure 1, D-G, and Supplemental Figure $1, E-G)$, suggesting that these cells may better resist advanced effector differentiation. Given that the distinctive properties accrued in the process of CD8 $8^{+} \mathrm{T}_{\mathrm{M}}$ aging can be efficiently passed on to $\mathrm{II}^{\circ} \mathrm{CD} 8^{+} \mathrm{T}_{\mathrm{M}}$ generations, we conclude that the original priming history shapes both $\mathrm{I}^{\circ}$ and $\mathrm{II}^{\circ} \mathrm{CD} 8^{+} \mathrm{T}$ cell memory formation as well as III ${ }^{\circ}$ reactivity.

Extended phenotypic and molecular $C D 8^{+} T_{M}$ conversion: towards homogeneity and naiveté. The changing phenotypic composition of the virus-specific $\mathrm{CD}^{+} \mathrm{T}_{\mathrm{M}}$ compartment could emerge from the progressive molecular/phenotypic conversion of individual $\mathrm{CD}^{+} \mathrm{T}_{\mathrm{M}}$ (4) or an outgrowth of $\mathrm{CD} 8^{+} \mathrm{T}_{\mathrm{M}}$ subsets with a competitive advantage (41). To distinguish between these possibilities, we built on our observation that aging $C D 8^{+} \mathrm{T}_{\mathrm{M}}$ substantially downregulated transcription/translation of CX3CR1 (Figure 10A). Using a mouse model in which $C \times 3 c r 1$ is replaced with a GFP reporter (44), GFP ${ }^{\text {hi }} \mathrm{CD} 8^{+} \mathrm{T}_{\mathrm{M}}$ were enriched from LCMV-immune heterozygous $\mathrm{C} \times 3 \mathrm{CrI}^{+/ / G f p}$ mice, labeled with a proliferation dye, and transferred into naive recipients (Figure 10B). Within $\sim 7$ weeks after AT, $\sim 15 \%-$ 
$20 \%$ of $\mathrm{D}^{\mathrm{b}} \mathrm{NP}_{396}{ }^{+} \mathrm{CD}^{+} \mathrm{T}_{\mathrm{M}}$ lost GFP expression without exhibiting signs of proliferation (Figure 10B), providing evidence that specific $\mathrm{CD}^{+} \mathrm{T}_{\mathrm{M}}$ are subject to a direct molecular conversion process, a conclusion consistent with earlier observations about $\mathrm{p} 14^{+}$or polyclonal $\mathrm{CD}^{+} \mathrm{T}_{\mathrm{M}}$ conversion at the level of CD62L re-expression $(12,40)$. Although the notions of $\mathrm{CD}^{+} \mathrm{T}_{\mathrm{M}}$ conversion and subset outgrowth are not mutually exclusive (40), the transformation of aging $\mathrm{CD}^{+} \mathrm{T}_{\mathrm{M}}$ phenotypes according to different rates and degrees (Figure 4, and Supplemental Figures 2 and 4-14) may be more effectively accounted for by the conversion model (experiments providing a more definitive answer to this question are in progress).

Despite preservation of some phenotypic heterogeneity even at very late memory stages, the long-term maintenance of $\mathrm{CD}^{+}$ $\mathrm{T}_{\mathrm{M}}$ populations appeared to result in the acquisition of more homogeneous appearances (Figure 4 and Supplemental Figures 5-14), an observation also made by Martin et al., who found fewer phenotypic subsets identified by 5-parameter Boolean gating in late versus early $\mathrm{p} 14^{+} \mathrm{T}_{\mathrm{CM}}$ populations (17). To evaluate this notion in our model, we determined the robust coefficient of variation (RCV) of marker expression and found that nearly $90 \%$ of CD8 ${ }^{+}$ $\mathrm{T}_{\mathrm{M}}$-expressed surface antigens (92 of 106) exhibited lower RCV values in old as compared with young $\mathrm{CD}^{+} \mathrm{T}_{\mathrm{M}}$, demonstrating that aging indeed fosters increased phenotypic homogeneity (Figure 10C). At the molecular level, our definition of unique young and old $\mathrm{p} 14^{+} \mathrm{T}_{\mathrm{M}}$ signatures also permitted their investigation by gene set enrichment analyses using published $\mathrm{CD}^{+} \mathrm{T}$ cell datasets comprising assorted specificities (TCRtg/tetramer ${ }^{+} / \mathrm{T}_{\mathrm{MP}}$ ), differentiation stages $\left(\mathrm{T}_{\mathrm{N}} / \mathrm{T}_{\mathrm{E}} ; \mathrm{I}^{\circ} / \mathrm{II}^{\circ} / \mathrm{III}^{\circ} \mathrm{T}_{\mathrm{M}}\right)$, subsets $\left(\mathrm{T}_{\mathrm{EM}} / \mathrm{T}_{\mathrm{CM}} / \mathrm{T}_{\mathrm{SCM}}\right)$, ages (young/old), operational states (resting/activated/exhausted), and species (murine/human). Altogether, we conducted 28 pairwise comparisons that confirmed the expected similarity of young $\mathrm{p} 14^{+} \mathrm{T}_{\mathrm{M}}$ to various resting $\mathrm{CD}^{+} \mathrm{T}_{\mathrm{M}}$ subsets but also revealed a notable enrichment of old $\mathrm{p} 14^{+} \mathrm{T}_{\mathrm{M}}$ signatures in both murine and human naive $\mathrm{CD}^{+} \mathrm{T}_{\mathrm{N}}$ (Figure 10D, Supplemental Figure 18, and data not shown). This conclusion was further supported by corresponding phenotypic analyses: relating the conversion trajectories of individual $\mathrm{CD}^{+} \mathrm{T}_{\mathrm{M}}$ markers to respective expression patterns of $\mathrm{CD}^{+} \mathrm{T}_{\mathrm{N}}$, we found that aging $\mathrm{CD} 8^{+} \mathrm{T}_{\mathrm{M}}$ gradually adopted an ever more naive phenotype (Figure 10E).

Given the unexpected constellation of increasing age, improved functionalities, and mostly naive $\mathrm{CD}^{+} \mathrm{T}_{\mathrm{M}}$ phenotypes, we revisited the notion of differential $\mathrm{I}^{\circ}$ versus $\mathrm{II}^{\circ}$ reactivity by directly comparing the proliferative capacity of $\mathrm{CD}^{+} \mathrm{T}_{\mathrm{N}}$ with that of young and old $\mathrm{CD}^{+} \mathrm{T}_{\mathrm{M}}$. Using the AT of limiting $\mathrm{p} 14^{+} \mathrm{T}_{\mathrm{N} / \mathrm{M}}$ numbers as an experimental tool to gauge their maximal proliferative potential, the $\mathrm{II}^{\circ}$ reactivity of old versus young $\mathrm{p} 14^{+} \mathrm{T}_{\mathrm{M}}$ was significantly enhanced as anticipated, but remarkably, even aged $\mathrm{p} 14^{+} \mathrm{T}_{\mathrm{M}}$ did not expand to the same extent as $\mathrm{p} 14^{+} \mathrm{T}_{\mathrm{N}}$ (Figure 10F). Thus, the evolution of aging $\mathrm{CD}^{+} \mathrm{T}_{\mathrm{M}}$ phenotypes and proliferative potential is marked by a progressive harmonization with $\mathrm{CD} 8^{+} \mathrm{T}_{\mathrm{N}}$ properties.

Differentiating $C D 8^{+} T_{M}$ subsets: memory markers old and new. What then are the distinctive phenotypic properties of mature CD $8^{+}$ $\mathrm{T}_{\mathrm{M}}$ and $\mathrm{CD}^{+} \mathrm{T}_{\mathrm{N}}$ populations? To some extent, the answer depends on the precise definition of $\mathrm{T}$ cell naiveté. Using the CD $44^{\text {lo }}$ status as a reference, the phenotypic conversion of aging $C D 8^{+} T_{M}$ did not produce populations identical to the $\mathrm{CD} 44^{\text {lo }} \mathrm{CD} 8^{+} \mathrm{T}_{\mathrm{N}}$ subset. Indeed, the analyses summarized in Figure $10 \mathrm{E}$ define multiple markers that distinguish mature $C D 8^{+} \mathrm{T}_{\mathrm{M}}$ from $\mathrm{CD} 44^{\mathrm{lo}} \mathrm{CD} 8^{+} \mathrm{T}_{\mathrm{N}}$, including several antigens not previously considered as memory markers (e.g., CD38, CD39, and CD47) (Supplemental Table 5 and Figure 11A). Alternatively, T cell naiveté can be defined as lack of prior exposure to specific antigens, and we reported earlier that up to $30 \%$ of the virus-specific $\mathrm{CD} 8^{+} \mathrm{T}$ cell repertoire in noninfected wild-type mice is in fact CD $44^{\text {hi }}$, a CD8 $8^{+} \mathrm{T}_{\mathrm{N}}$ subset termed "virtual memory" cells $\left(C D 8^{+} \mathrm{T}_{\mathrm{VM}}\right)$ (45). As shown here, $\mathrm{CD} 8^{+} \mathrm{T}_{\mathrm{VM}}$ and $\mathrm{T}_{\mathrm{MP}}$ exhibited largely shared memory marker signatures, and a comparison of virus-specific and bulk $\mathrm{CD} 44^{\text {lo }} \mathrm{CD} 8^{+} \mathrm{T}_{\mathrm{N}}$ also revealed essentially identical phenotypes (Figure 11, A and B). While CD8 ${ }^{+}$ $\mathrm{T}_{\mathrm{VM}}$ and $\mathrm{T}_{\mathrm{MP}}$ were somewhat similar to $\mathrm{CD} 44^{\mathrm{lo}} \mathrm{CD}^{+} \mathrm{T}_{\mathrm{N}}\left(\mathrm{CD} 39^{-}\right.$ Sca- $\left.1^{\text {lo }} \mathrm{NKG} 2 \mathrm{D}^{-} \mathrm{GITR}^{\mathrm{lo}}\right)$ or of a mixed phenotype (CD $\left.47^{\text {int }} \mathrm{CD} 38^{\text {int }}\right)$, they also exhibited key features of aged $\mathrm{CD}^{+} \mathrm{T}_{\mathrm{M}}\left(\mathrm{CXCR} 3^{+} \mathrm{CD} 122^{\text {hi }}\right.$ integrin $\beta_{7}^{\text {lo }} \mathrm{Gr}-1 / \mathrm{Ly}_{6} \mathrm{C}^{\text {hi }} \mathrm{IL}-18 \mathrm{Ra}^{+} \mathrm{CCR} 9^{-}$) (Figure 11, A and B). Furthermore, expression of integrin $\alpha_{4}$, widely used as a genuine memory marker and found at low levels on CD8 ${ }^{+} \mathrm{T}_{\mathrm{VM}}$ (45), was in fact gradually downmodulated by aging $C D 8^{+} \mathrm{T}_{\mathrm{M}}$ (Figure $11 \mathrm{C}$ ). Taking into account the residual phenotypic heterogeneity of aged $\mathrm{CD}^{+} \mathrm{T}_{\mathrm{M}}$ populations and the constitutive diversity of $\mathrm{CD}^{+} \mathrm{T}_{\mathrm{N}}$ comprising both $\mathrm{CD} 44^{\text {lo }}$ and $\mathrm{CD} 44^{\text {hi }}$ subsets, their overall similarity therefore appears even more striking.

$C D 8^{+} T_{M}$ aging as a dedifferentiation process: the rebound model of $T_{M}$ maturation. From the perspective of the extended and cumulative $C D 8^{+} \mathrm{T}_{\mathrm{M}}$ maturation process, our results suggest a simple amendment to the decreasing potential model of $\mathrm{T}_{\mathrm{M}}$ generation $(1,4)$ : improved $\mathrm{II}^{\circ} \mathrm{CD}^{+} \mathrm{T}_{\mathrm{M}}$ reactivity and associated protective capacity develop with a probability and at a pace inversely proportional to the extent of $\mathrm{I}^{\circ} \mathrm{CD}^{+} \mathrm{T}_{\mathrm{E}}$ differentiation. This contention, based on a reevaluation of earlier observations $(2,40)$ in the expanded context of $\mathrm{CD}^{+} \mathrm{T}_{\mathrm{M}}$ aging developed here, is further supported by our in vivo titration experiments demonstrating that the $\mathrm{CD}^{+} \mathrm{T}_{\mathrm{M}}$ aging process at large can be accelerated or delayed by simply manipulating the conditions of initial $\mathrm{CD}^{+} \mathrm{T}_{\mathrm{E}}$ priming. Accordingly, the degree of $\mathrm{I}^{\circ} \mathrm{CD}^{+} \mathrm{T}_{\mathrm{E}}$ differentiation, primarily a product of pathogen replication/dissemination, inflammation, and reciprocal $\mathrm{CD} 8^{+} \mathrm{T}_{\mathrm{N}}$ precursor frequency that together control the speed and relative extent of proliferative $C D 8^{+} T_{E}$ expansion, directly determines the odds and kinetics with which, over a period of months to years, $\mathrm{CD}^{+} \mathrm{T}_{\mathrm{M}}$ and $\mathrm{T}_{\mathrm{N}}$ properties are progressively aligned (Figure 11D).

The notion of shared features between $\mathrm{CD}^{+} \mathrm{T}_{\mathrm{M}}$ and $\mathrm{T}_{\mathrm{N}}$ is also supported by global transcriptome analyses of murine and human $\mathrm{CD}^{+} \mathrm{T}$ cell subsets that overall reveal a substantial degree of similarity ( 95\%) (46), and that position $\mathrm{CD}^{+} \mathrm{T}_{\mathrm{M}}, \mathrm{T}_{\mathrm{CM}}$, or $\mathrm{T}_{\mathrm{SCM}}$ populations, respectively, in increasing proximity to $\mathrm{CD}^{+} \mathrm{T}_{\mathrm{N}}(31,47-49)$. And although $\mathrm{CD}^{+} \mathrm{T}_{\mathrm{M}}$ are traditionally regarded as more potent, recent studies have identified several advantageous properties of $\mathrm{CD}^{+} \mathrm{T}_{\mathrm{N}}$ in comparison with $\mathrm{CD}^{+} \mathrm{T}_{\mathrm{CM}}$ subsets, such as their reduced antigen threshold requirements (50), their greater capacity for generation of $C D 8^{+} \mathrm{T}_{\mathrm{E}}$ with superior proliferative and antitumor potential (51), or the better expansion of OT- $\mathrm{I}^{+}$and $\mathrm{p}^{+} 4^{+} \mathrm{T}_{\mathrm{N}}$ in relation to various $\mathrm{CD}^{+} \mathrm{T}_{\mathrm{M}}$ populations (total $\mathrm{T}_{\mathrm{M}} / \mathrm{T}_{\mathrm{EM}} / \mathrm{T}_{\mathrm{CM}}$ ) following bacterial or LCMV cl13 challenge $(16,52)$. If $\mathrm{CD}^{+} \mathrm{T}_{\mathrm{M}}$, in comparison with $\mathrm{CD}^{+} \mathrm{T}_{\mathrm{N}}$, therefore can be said to have traded potential (i.e., the entire range of possible features to be acquired within the context of $\mathrm{I}^{\circ}$ response) for potency (i.e., the more limited spectrum 
of actual $\mathrm{CD}^{+} \mathrm{T}_{\mathrm{M}}$ properties), the transcriptional, phenotypic, and functional alterations accrued during their prolonged maturation not only suggest a partial reacquisition of the potential inherent to $\mathrm{CD} 8^{+} \mathrm{T}_{\mathrm{N}}$, but in fact a process of dedifferentiation we refer to as the "rebound model" of $\mathrm{T}_{\mathrm{M}}$ maturation (Figure 11D).

However, the acquisition of certain features clearly marks aged $\mathrm{CD}^{+} \mathrm{T}_{\mathrm{M}}$ as distinct from $\mathrm{CD} 8^{+} \mathrm{T}_{\mathrm{N}}$ (Figure 11A), and the peculiar blend of naive and memory properties intimates a pronounced similarity to $\mathrm{T}_{\mathrm{SCM}}$ : with the exception of CD44 expression, aged $\mathrm{CD}^{+} \mathrm{T}_{\mathrm{M}}$ not only conform to the murine $\mathrm{CD} 8^{+} \mathrm{T}_{\mathrm{SCM}}$ phenotype (28), but bear an extraordinary resemblance to the more extensively characterized human $\mathrm{CD}^{+} \mathrm{T}_{\mathrm{SCM}}$ population (Supplemental Table 6) with whom they also share superior proliferative and protective potential (49). However, while Gattinoni et al. proposed a scheme that positions $\mathrm{T}_{\mathrm{SCM}}$ as the least differentiated $\mathrm{CD}^{+} \mathrm{T}_{\mathrm{M}}$ subset in a developmental progression that casts the acquisition of stem cell-like properties as the result of arrested $\mathrm{T}$ cell differentiation $\left(\mathrm{T}_{\mathrm{N}} \rightarrow \mathrm{T}_{\mathrm{SCM}} \rightarrow \mathrm{T}_{\mathrm{CM}} \rightarrow \mathrm{T}_{\mathrm{EM}} \rightarrow \mathrm{T}_{\mathrm{E}}\right.$ ), the "rebound model" posits that $\mathrm{T}_{\mathrm{SCM}}$-like $\mathrm{CD} 8^{+} \mathrm{T}_{\mathrm{M}}$ populations constitute a late, advanced, perhaps even "terminally dedifferentiated" stage in the extended CD8 ${ }^{+} \mathrm{T}_{\mathrm{M}}$ maturation process ( $\mathrm{T}_{\mathrm{N}} \rightarrow \mathrm{T}_{\mathrm{E}} \rightarrow \mathrm{T}_{\mathrm{EM}} \rightarrow \mathrm{T}_{\mathrm{CM}} \rightarrow \mathrm{T}_{\mathrm{SCM}}$-like) (Figure 11D).

\section{Discussion}

The aging immune system is subject to a confluence of complex adaptations that collectively can compromise specific $\mathrm{T}$ cell immunity in particular, immune homeostasis and protection in general, and therefore health and longevity at large (5-10). In apparent contrast, we demonstrate that prolonged preservation of $\mathrm{CD}^{+} \mathrm{T}_{\mathrm{M}}$ populations specific for an acute viral pathogen promotes a series of extensive adaptations that impart enhanced $\mathrm{II}^{\circ}$ reactivity and improved protective capacity unto aging $\mathrm{CD}^{+} \mathrm{T}_{\mathrm{M}}$. With the rebound model of $C D 8^{+} \mathrm{T}_{\mathrm{M}}$ maturation, we have further developed a conceptual and actionable framework that integrates these manifold dynamics with earlier findings about slowly changing $\mathrm{CD}^{+} \mathrm{T}_{\mathrm{M}}$ properties including a most recent distinction between early and late $\mathrm{CD} 8^{+} \mathrm{T}_{\mathrm{CM}}$ attributes, as documented by Martin et al. (11-17). The precise correlation of proliferative potential and protection, however, is more complex since it is shaped by the nature of the infection (pathogen, route, dosage), the number of available $\mathrm{CD}^{+} \mathrm{T}_{\mathrm{M}}$, their $\mathrm{II}^{\circ}$ reactivity and access to the sites of infection, and the coordinated deployment of various effector functions. In some settings, $\mathrm{CD}^{+} \mathrm{T}_{\mathrm{M}}$ populations with more effector-like properties were shown to provide better protection despite poor $\mathrm{II}^{\circ}$ expansion $(20,53)$. Such observations certainly underscore the challenges associated with the definition of general principles applicable to $\mathrm{T}$ cell-mediated immune protection, but it should also be noted that clinically relevant differences (e.g., the level of infectious pathogen) may emerge at times only under very specific experimental conditions (e.g., the "right" combination of transferred $C D 8^{+} \mathrm{T}_{\mathrm{M}}$ numbers, pathogen challenge dosage, and timing of analyses). Therefore, a combinatorial analysis of such experimental parameters will be particularly informative (52).

The prolonged nature of the $\mathrm{CD}^{+} \mathrm{T}_{\mathrm{M}}$ maturation process described here reinforces the notion of early $\mathrm{I}^{\circ}$ immunization and delayed booster regimens as a preferred vaccination strategy (3), an approach that can be refined through heterologous prime-boost (HPB) vaccinations of intact hosts that promote stepwise enlarge- ments of specific $\mathrm{CD}^{+} \mathrm{T}_{\mathrm{M}}$ pools and thus can precipitate improved higher-order recall responses and $\mathrm{CD}^{+} \mathrm{T}_{\mathrm{M}}$ formation (54). However, in agreement with the rebound model, HPB vaccination fails to generate superior $\mathrm{CD}^{+} \mathrm{T}_{\mathrm{M}}$ populations in experimental settings that limit available $\mathrm{CD}^{+} \mathrm{T}_{\mathrm{M}}$ numbers (54), emphasizing that the maturation kinetics of $\mathrm{CD}^{+} \mathrm{T}_{\mathrm{M}}$ populations, and with that effective immune protection, are contingent on the specific conditions of their generation. Of particular note here is the precise temporal development of the $\mathrm{I}^{\circ} \mathrm{CD} 8^{+} \mathrm{T}_{\mathrm{E}}$ response, i.e., the combination of $\mathrm{I}^{\circ}$ $C D 8^{+} T_{E}$ population growth rates and relative $C D 8^{+} T_{E}$ burst sizes that determines the pace at which mature phenotypic and functional $\mathrm{CD}^{+} \mathrm{T}_{\mathrm{M}}$ properties are acquired at large (Figure 11D). In the case of recall responses, the speed of $\mathrm{II}^{\circ} \mathrm{CD} 8^{+} \mathrm{T}$ cell memory formation is further contingent on the relative survival of $\mathrm{II}^{\circ} \mathrm{CD}^{+}$ $\mathrm{T}_{\mathrm{E}}$ populations, itself a function of $\mathrm{I}^{\circ} \mathrm{CD} 8^{+} \mathrm{T}_{\mathrm{M}}$ maturation stage, such that accelerated $\mathrm{II}^{\circ} \mathrm{CD}^{+} \mathrm{T}_{\mathrm{M}}$ development may occur despite greater $\mathrm{II}^{\circ} \mathrm{CD}^{+} \mathrm{T}_{\mathrm{E}}$ expansion; similar considerations likely apply to the establishment of $\mathrm{III}^{\circ}$ and higher-order memory, though the respective $C D 8^{+} T_{M}$ dedifferentiation processes are progressively delayed or rendered abortive (55).

Our results further indicate that age-associated deteriorations of $\mathrm{T}$ cell immunity may be restricted to particular subsets (e.g., $\mathrm{T}_{\mathrm{N}}$ or $\mathrm{T}_{\mathrm{M}}$ specific for persistent pathogens) $(5,8,10,22)$ while others, as shown here for bona fide pathogen-specific $\mathrm{CD} 8^{+} \mathrm{T}_{\mathrm{M}}$, are not only spared but apparently improve over time. The extent to which similar processes are operative in humans remains to be investigated by an expansion of longitudinal analyses such as those of Miller et al. (56) or the recent cross-sectional survey of major $\mathrm{T}$ cell subsets in multiple tissues across 6 decades of life by Thome et al. (57). The conceptualization of $\mathrm{T}$ cell memory as an extended dedifferentiation process in the wake of a defined stimulatory event, however, will have ramifications beyond the context of aging: the introduction of time as an organizing principle for the astonishing phenotypic and functional heterogeneity of the $\mathrm{T}_{\mathrm{M}}$ compartment (58) provides a simple ontogenetic perspective that can account for the relational complexity of numerous $\mathrm{CD}^{+} \mathrm{T}_{\mathrm{M}}$ properties, and that may conceive of altered $\mathrm{T}$ cell modalities observed under conditions of repeated pathogen exposure, persistent infection, absence of $\mathrm{CD}^{+} \mathrm{T}$ cell help or age-associated formation of clonal expansions as instances of delayed, aborted, impaired, or divergent dedifferentiation. That the rebound model contributes to an integrated and facilitated understanding of the organization of $\mathrm{T}$ cell memory, to the efficient identification of relevant molecular pathways in control of changing homeostatic and recall CD8 ${ }^{+} \mathrm{T}_{\mathrm{M}}$ properties, and to the improved practical coordination of diagnostic, prophylactic, and therapeutic interventions will be a condition of its utility.

\section{Methods}

Mice, viruses, and challenge protocols. C57BL6/J, congenic B6.CD90.1 and B6.CD45.1, and B6.CD45.1.CX3CR1 $1^{\text {Gf } / G f p}$, and OT-I mice were purchased from The Jackson Laboratory; p14 mice were obtained on a B6.CD90.1 background from M. Oldstone (The Scripps Research Institute, La Jolla, California, USA). We only used male mice in this study to avoid potential artifacts due to gender-mismatched AT settings. LCMV Armstrong (clone 53b) and cl13 were provided by M. Oldstone and grown and titered as described $(11,35)$. Eight- to ten-weekold mice were inoculated i.p. with $2 \times 10^{5}$ PFU LCMV Armstrong; in 
some cases, graded dosages $\left(2 \times 10^{3}\right.$ to $\left.2 \times 10^{7} \mathrm{PFU}\right)$ of LCMV Armstrong were used (Figure 9). For $\mathrm{II}^{\circ}$ challenges, recipients of $\mathrm{CD}^{+} \mathrm{T}_{\mathrm{M}}$ were inoculated i.p. with $2 \times 10^{5} \mathrm{PFU}$ LCMV Armstrong or $2 \times 10^{6} \mathrm{PFU}$ LCMV cl13 i.v. Aging LCMV-immune mice were excluded if they presented with the following conditions: (a) gross physical abnormalities (lesions, emaciation, weight loss); (b) lymphatic tumors at time of necropsy; or (3) $\mathrm{T}$ cell clonal expansions in the $\mathrm{D}^{\mathrm{b}} \mathrm{NP}_{396}{ }^{+}, \mathrm{D}^{\mathrm{b}} \mathrm{GP}_{33}{ }^{+}$, or $\mathrm{D}^{\mathrm{b}} \mathrm{GP}_{276}{ }^{+} \mathrm{CD}^{+} \mathrm{T}_{\mathrm{M}}$ compartment. According to these criteria, up to $\sim 30 \%$ of aging mice were excluded from the study.

Tissue processing, cell purification, adoptive transfers, and flow cytometry. Standard protocols and procedures were employed as detailed in Supplemental Methods.

Microarray hybridization and analysis. $\mathrm{p}^{+} 4^{+} \mathrm{T}_{\mathrm{E} / \mathrm{M}}$ were generated as shown in Figure 3A, purified to greater than $99 \%$, and processed for hybridization to Affymetrix M430.2 arrays as detailed in Supplemental Methods; the data can be retrieved from the NCBI's Gene Expression Omnibus (GEO GSE38462).

Statistics. Data handling, analysis, and graphic representation was performed using Prism 6.0 (GraphPad Software). All data summarized in bar and line diagrams are expressed as the mean \pm 1 SEM and asterisks indicate statistical differences calculated, where applicable, by 1-way ANOVA with Dunnett's multiple comparisons or Student's $t$ test (2-tailed unpaired or paired); a $P$ value of $<0.05$ was considered significant $\left({ }^{*} P<0.05,{ }^{* *} P<0.01\right.$, and $\left.{ }^{* * *} P<0.001\right)$.

Study approval. All procedures involving laboratory animals were conducted in accordance with the recommendations in the NIH "Guide for the Care and Use of Laboratory Animals", protocols were approved by Institutional Animal Care and Use Committees of the University of Colorado (70205604[05]1F, 70205607[05]4F, B-70210[05]1E) and
Icahn School of Medicine at Mount Sinai (IACUC-2014-0170), and all efforts were made to minimize suffering of animals.

\section{Author contributions}

JE, BD, and DH designed the study and individual experiments; JE, BD, TTN, FV, KH, KJ, RMK, ETC, and DH conducted experiments and acquired data; JE, BD, AKF, LEH, RMK, ETC, and DH analyzed data; RMK provided reagents; and DH wrote the manuscript.

\section{Acknowledgments}

We thank J. Browning, L. Justement, M. Mack, M. Taniguchi, and W. Yokoyama for the gift of several unique antibodies (Supplemental Table 7), A. Rubtsov for blood samples from unmanipulated aging B6 cohorts, M. Cikara for assistance with serum cytokine analyses, B. Aguado for a list of Ly6SF genes, and P. Marrack for critical manuscript reading. This work was supported by NIH grants AG026518 and AI093637, Juvenile Diabetes Research Foundation grant CDA-2-2007-240, and Diabetes and Endocrinology Research Center grant P30-DK057516 (to D. Homann), NIH grants LM008111 and LM009254 (to L. Hunter), NIH grants AI06877 and AI066121 (to R. Kedl), American Heart Association grant 13SDG14510023 (to E. Clambey), and NIH grants T32 AI007405 and AI052066 (to B. Davenport).

Address correspondence to: Dirk Homann, Diabetes Obesity Metabolism and Immunology Institutes, Icahn School of Medicine at Mount Sinai, One Gustave L. Levy Place - Box 1152, New York, New York 10029, USA. Phone: 212.241.1935; E-mail: dirk. homann@mssm.edu.
1. Kaech SM, Wherry EJ. Heterogeneity and cellfate decisions in effector and memory $\mathrm{CD}^{+} \mathrm{T}$ cell differentiation during viral infection. Immunity. 2007;27(3):393-405.

2. Harty JT, Badovinac VP. Shaping and reshaping $\mathrm{CD}^{+}$T-cell memory. Nat Rev Immunol. 2008;8(2):107-119.

3. Sallusto F, Lanzavecchia A, Araki K, Ahmed R. From vaccines to memory and back. Immunity. 2010;33(4):451-463.

4. Cui W, Kaech SM. Generation of effector CD8 ${ }^{+}$ $\mathrm{T}$ cells and their conversion to memory T cells. Immunol Rev. 2010;236:151-166.

5. Buchholz VR, Neuenhahn M, Busch DH. CD8 ${ }^{+} \mathrm{T}$ cell differentiation in the aging immune system: until the last clone standing. Curr Opin Immunol. 2011;23(4):549-554.

6. Akbar AN, Henson SM. Are senescence and exhaustion intertwined or unrelated processes that compromise immunity? Nat Rev Immunol. 2011;11(4):289-295.

7. Blackman MA, Woodland DL. Impact of aging on $\mathrm{T}$ cell repertoire and immunity. In: Massoud A, Rezaei N, eds. Immunology of Aging. Springer Berlin Heidelberg; 2013:145-159.

8. Fülöp T, Larbi A, Pawelec G. Human T cell aging and the impact of persistent viral infections. Front Immunol. 2013;4:271.

9. Chen G, Lustig A, Weng NP. T cell aging: a review of the transcriptional changes determined from genome-wide analysis. Front Immunol.

\section{3;4:121.}

10. Nikolich-Žugich J. Aging of the T cell compartment in mice and humans: from no naive expectations to foggy memories. Jimmunol. 2014;193(6):2622-2629.

11. Homann D, Teyton L, Oldstone MB. Differential regulation of antiviral $\mathrm{T}$-cell immunity results in stable $\mathrm{CD}^{+}$but declining $\mathrm{CD}^{+}{ }^{+} \mathrm{T}$-cell memory. Nat Med. 2001;7(8):913-919.

12. Wherry EJ, et al. Lineage relationship and protective immunity of memory CD8 T cell subsets. Nat Immunol. 2003;4(3):225-234.

13. Hikono H, Kohlmeier JE, Takamura S, Wittmer ST, Roberts AD, Woodland DL. Activation phenotype, rather than central- or effector-memory phenotype, predicts the recall efficacy of memory CD8 ${ }^{+}$T cells. J Exp Med. 2007;204(7):1625-1636.

14. Roberts AD, Ely KH, Woodland DL. Differential contributions of central and effector memory T cells to recall responses. J Exp Med. 2005;202(1):123-133.

15. Wherry EJ, et al. Molecular signature of $C D 8^{+} \mathrm{T}$ cell exhaustion during chronic viral infection. Immunity. 2007;27(4):670-684.

16. Martin MD, Condotta SA, Harty JT, Badovinac VP. Population dynamics of naive and memory CD8 T cell responses after antigen stimulations in vivo. JImmunol. 2012;188(3):1255-1265.

17. Martin MD, et al. Phenotypic and functional alterations in circulating memory CD8 T cells with time after primary infection. PLoS Pathog. 2015;11(10):e1005219.

18. Eberlein J, Nguyen TT, Victorino F, Golden-Mason L, Rosen HR, Homann D. Comprehensive assessment of chemokine expression profiles by flow cytometry. J Clin Invest. 2010;120(3):907-923.

19. Whitmire JK, Eam B, Whitton JL. Tentative T cells: memory cells are quick to respond, but slow to divide. PLoS Pathog. 2008;4(4):e1000041.

20. Nolz JC, Harty JT. Protective capacity of memory $\mathrm{CD}^{+} \mathrm{T}$ cells is dictated by antigen exposure history and nature of the infection. Immunity. 2011;34(5):781-793.

21. Olson MR, McDermott DS, Varga SM. The initial draining lymph node primes the bulk of the CD8 $\mathrm{T}$ cell response and influences memory $\mathrm{T}$ cell trafficking after a systemic viral infection. PLoS Pathog. 2012;8(12):e1003054.

22. Decman V, et al. Defective CD8 T cell responses in aged mice are due to quantitative and qualitative changes in virus-specific precursors. J Immunol. 2012;188(4):1933-1941.

23. McGavern DB, Truong P. Rebuilding an immune-mediated central nervous system disease: weighing the pathogenicity of antigen-specific versus bystander T cells. J Immunol. 2004;173(8):4779-4790.

24. Masopust D, Ha SJ, Vezys V, Ahmed R. Stimulation history dictates memory CD8 T cell phenotype: implications for prime-boost vaccination. JImmunol. 2006;177(2):831-839.

25. Brooks DG, Trifilo MJ, Edelmann KH, Teyton 
L, McGavern DB, Oldstone MB. Interleukin-10 determines viral clearance or persistence in vivo. Nat Med. 2006;12(11):1301-1309.

26. Tinoco R, Alcalde V, Yang Y, Sauer K, Zuniga EI. Cell-intrinsic transforming growth factor-beta signaling mediates virus-specific $\mathrm{CD} 8^{+} \mathrm{T}$ cell deletion and viral persistence in vivo. Immunity 2009;31(1):145-157.

27. Harker JA, Lewis GM, Mack L, Zuniga EI. Late interleukin- 6 escalates $T$ follicular helper cell responses and controls a chronic viral infection. Science. 2011;334(6057):825-829.

28. Gattinoni L, Klebanoff CA, Restifo NP. Paths to stemness: building the ultimate antitumour $\mathrm{T}$ cell. Nat Rev Cancer. 2012;12(10):671-684.

29. Coles MC, McMahon CW, Takizawa H, Raulet DH. Memory CD8 T lymphocytes express inhibitory MHC-specific Ly 49 receptors. Eur J Immunol. 2000;30(1):236-244.

30. Mueller SN, Gebhardt T, Carbone FR, Heath WR. Memory T cell subsets, migration patterns, and tissue residence. Annu Rev Immunol. 2013;31:137-161.

31. Kaech SM, Hemby S, Kersh E, Ahmed R. Molecular and functional profiling of memory CD8 T cell differentiation. Cell. 2002;111(6):837-851.

32. Zhu Y, Yao S, Chen L. Cell surface signaling molecules in the control of immune responses: a tide model. Immunity. 2011;34(4):466-478.

33. Sallusto F, Geginat J, Lanzavecchia A. Central memory and effector memory $\mathrm{T}$ cell subsets: function, generation, and maintenance. Annu Rev Immunol. 2004;22:745-763.

34. Feau S, Arens R, Togher S, Schoenberger SP. Autocrine IL-2 is required for secondary population expansion of CD8(+) memory T cells. Nat Immunol. 2011;12(9):908-913.

35. Hildemann SK, Eberlein J, Davenport B, Nguyen TT, Victorino F, Homann D. High efficiency of antiviral CD4(+) killer T cells. PLoS One. 2013;8(4):e60420.

36. Rock MT, Yoder SM, Wright PF, Talbot TR, Edwards KM, Crowe JE. Differential regulation of granzyme and perforin in effector and memory $\mathrm{T}$ cells following smallpox immunization.
J Immunol. 2005;174(6):3757-3764.

37. Böttcher JP, et al. Functional classification of memory CD8(+) T cells by CX3CR1 expression. Nat Commun. 2015;6:8306.

38. Barber DL, Wherry EJ, Ahmed R. Cutting edge: rapid in vivo killing by memory CD8 $\mathrm{T}$ cells. J Immunol. 2003;171(1):27-31.

39. Buchholz VR, Schumacher TN, Busch DH. T cell fate at the single-cell level. Annu Rev Immunol. 2016;34:65-92.

40. Sarkar S, et al. Strength of stimulus and clonal competition impact the rate of memory CD8 T cell differentiation. J Immunol. 2007;179(10):6704-6714

41. Obar JJ, Lefrançois L. Memory CD8 ${ }^{+} \mathrm{T}$ cell differ entiation. Ann N Y Acad Sci. 2010;1183:251-266.

42. Joshi NS, Cui W, Dominguez CX, Chen JH, Hand TW, Kaech SM. Increased numbers of preexisting memory CD8 T cells and decreased T-bet expression can restrain terminal differentiation of secondary effector and memory CD8 T cells. JImmunol. 2011;187(8):4068-4076.

43. Khan SH, Martin MD, Starbeck-Miller GR, Xue HH, Harty JT, Badovinac VP. The timing of stimulation and IL-2 signaling regulate secondary CD8 T cell responses. PLoS Pathog. 2015;11(10):e1005199.

44. Jung S, et al. Analysis of fractalkine receptor CX(3)CR1 function by targeted deletion and green fluorescent protein reporter gene insertion. Mol Cell Biol. 2000;20(11):4106-4114.

45. Haluszczak C, et al. The antigen-specific $\mathrm{CD}^{+} \mathrm{T}$ cell repertoire in unimmunized mice includes memory phenotype cells bearing markers of homeostatic expansion. JExp Med. 2009;206(2):435-448.

46. Weng NP, Araki Y, Subedi K. The molecular basis of the memory $\mathrm{T}$ cell response: differential gene expression and its epigenetic regulation. Nat Rev Immunol. 2012;12(4):306-315.

47. Holmes S, He M, Xu T, Lee PP. Memory T cells have gene expression patterns intermediate between naive and effector. Proc Natl Acad Sci US A. 2005;102(15):5519-5523.
48. Willinger T, Freeman T, Hasegawa H, McMichael AJ, Callan MF. Molecular signatures distinguish human central memory from effector memory CD8 T cell subsets. JImmunol. 2005;175(9):5895-5903.

49. Gattinoni L, et al. A human memory T cell subset with stem cell-like properties. Nat Med. 2011;17(10):1290-1297.

50. Mehlhop-Williams ER, Bevan MJ. Memory $\mathrm{CD}^{+} \mathrm{T}$ cells exhibit increased antigen threshold requirements for recall proliferation. J Exp Med. 2014;211(2):345-356.

51. Hinrichs CS, Rosenberg SA. Exploiting the curative potential of adoptive T-cell therapy for cancer. Immunol Rev. 2014;257(1):56-71.

52. West EE, et al. Tight regulation of memory CD8(+) T cells limits their effectiveness during sustained high viral load. Immunity. 2011;35(2):285-298.

53. Olson JA, McDonald-Hyman C, Jameson SC, Hamilton SE. Effector-like CD8 ${ }^{+} \mathrm{T}$ cells in the memory population mediate potent protective immunity. Immunity. 2013;38(6):1250-1260.

54. Fraser KA, Schenkel JM, Jameson SC, Vezys V, Masopust D. Preexisting high frequencies of memory $\mathrm{CD}^{+} \mathrm{T}$ cells favor rapid memory differentiation and preservation of proliferative potential upon boosting. Immunity. 2013;39(1):171-183.

55. Wirth TC, et al. Repetitive antigen stimulation induces stepwise transcriptome diversification but preserves a core signature of memory CD8(+) T cell differentiation. Immunity. 2010;33(1):128-140.

56. Miller JD, et al. Human effector and memory $\mathrm{CD}^{+} \mathrm{T}$ cell responses to smallpox and yellow fever vaccines. Immunity. 2008;28(5):710-722.

57. Thome JJ, et al. Spatial map of human T cell compartmentalization and maintenance over decades of life. Cell. 2014;159(4):814-828.

58. Newell EW, Sigal N, Bendall SC, Nolan GP, Davi MM. Cytometry by time-of-flight shows combinatorial cytokine expression and virus-specific cell niches within a continuum of $\mathrm{CD}^{+} \mathrm{T}$ cell phenotypes. Immunity. 2012;36(1):142-152. 